Cochrane Database of Systematic Reviews

\title{
Adjuvant chemotherapy for advanced endometrial cancer (Review)
}

Galaal K, Al Moundhri M, Bryant A, Lopes AD, Lawrie TA

Galaal K, Al Moundhri M, Bryant A, Lopes AD, Lawrie TA.

Adjuvant chemotherapy for advanced endometrial cancer.

Cochrane Database of Systematic Reviews 2014, Issue 5. Art. No.: CD010681.

DOI: 10.1002/14651858.CD010681.pub2.

www.cochranelibrary.com 
TABLE OF CONTENTS

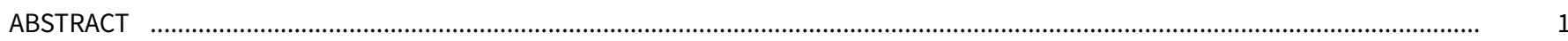

PLAIN LANGUAGE SUMMARY

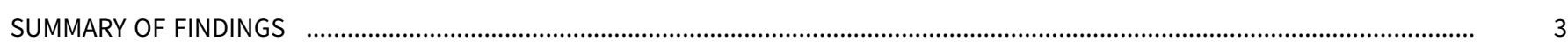

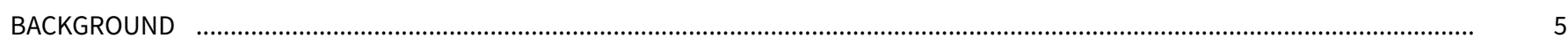

OBJECTIVES

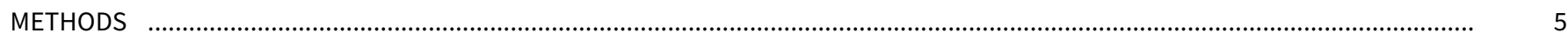

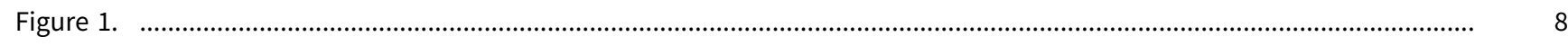

RESULTS

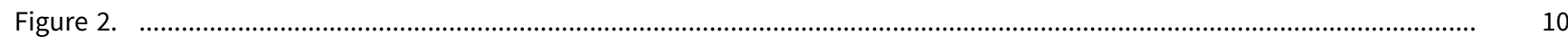

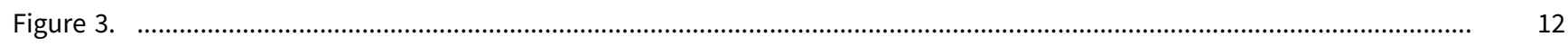

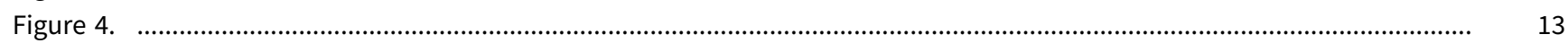

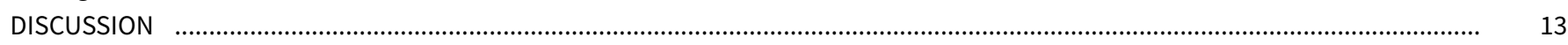

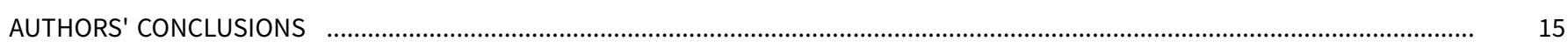

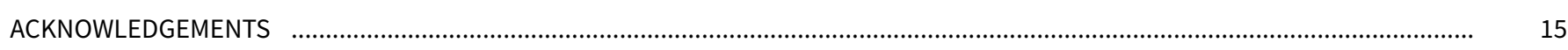

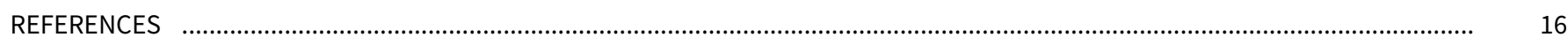

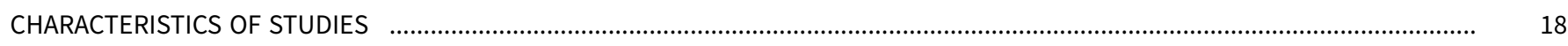

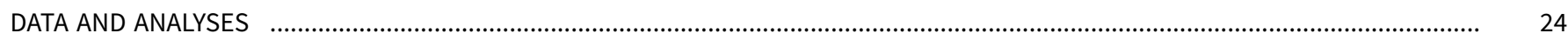

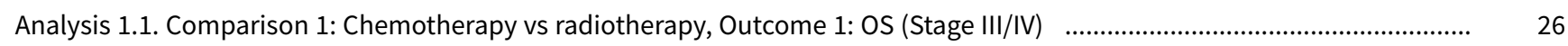

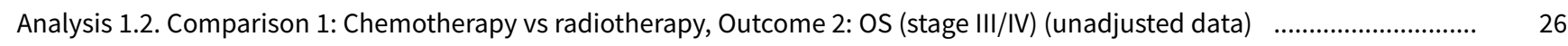

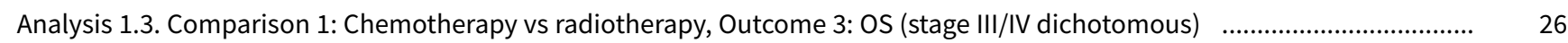

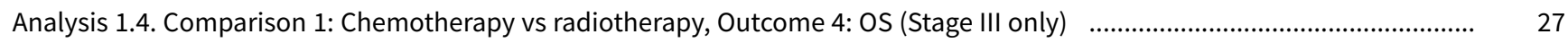

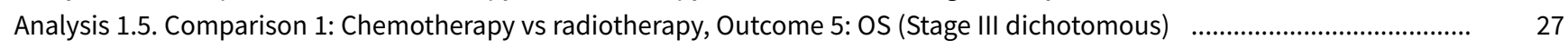

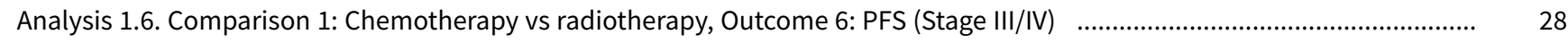

Analysis 1.7. Comparison 1: Chemotherapy vs radiotherapy, Outcome 7: PFS (stage III/IV dichotomous) ................................... 28

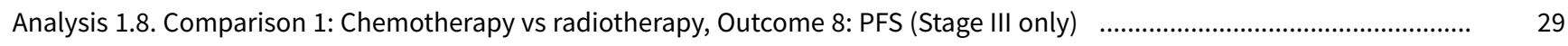

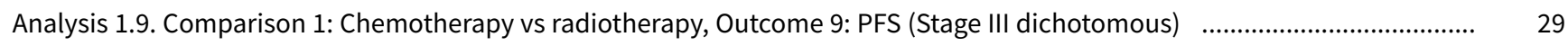

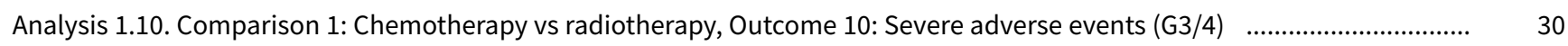

Analysis 1.11. Comparison 1: Chemotherapy vs radiotherapy, Outcome 11: Treatment discontinuation due to toxicity $\quad . . . . . . . . . . . \quad 30$

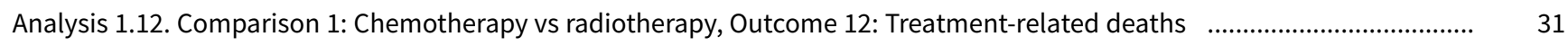

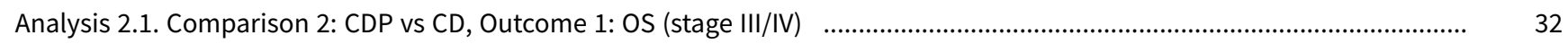

Analysis 2.2. Comparison 2: CDP vs CD, Outcome 2: PFS (stage III/IV)

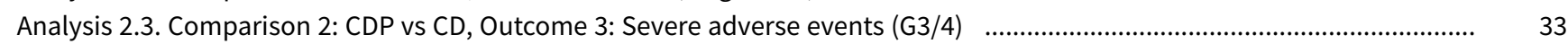

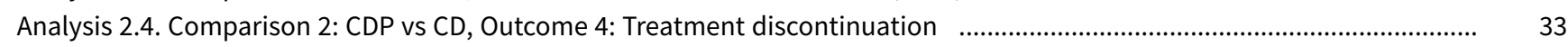

APPENDICES

WHAT'S NEW

HISTORY

CONTRIBUTIONS OF AUTHORS

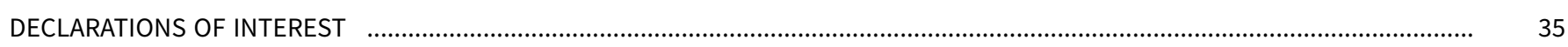

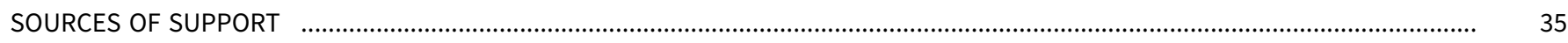

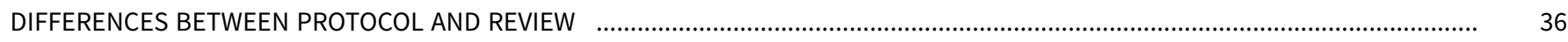

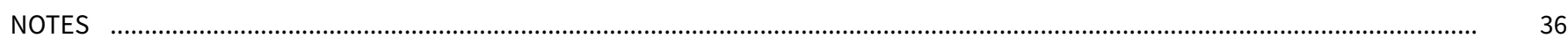

INDEX TERMS 
[Intervention Review]

\section{Adjuvant chemotherapy for advanced endometrial cancer}

Khadra Galaal ${ }^{1}$, Mansour Al Moundhri², Andrew Bryant ${ }^{3}$, Alberto D Lopes ${ }^{4}$, Theresa A Lawrie ${ }^{5}$

1Gynaecological Oncology, Princess Alexandra Wing, Royal Cornwall Hospital, Truro, UK. 2Medical Oncology Unit, Department of Medicine, College of Medicine and Health Sciences and Sultan Qaboos University Hospital, Al-Khod, Oman. ${ }^{3}$ Institute of Health \& Society, Newcastle University, Newcastle upon Tyne, UK. ${ }^{4}$ University of Exeter Medical School, Exeter, UK. ${ }^{5}$ The Evidence-Based Medicine Consultancy Ltd, Bath, UK

Contact: Khadra Galaal, k.galaal@nhs.net, khadragalaal@yahoo.co.uk.

Editorial group: Cochrane Gynaecological, Neuro-oncology and Orphan Cancer Group.

Publication status and date: Stable (no update expected for reasons given in 'What's new'), published in Issue 5, 2021.

Citation: Galaal K, Al Moundhri M, Bryant A, Lopes AD, Lawrie TA. Adjuvant chemotherapy for advanced endometrial cancer. Cochrane Database of Systematic Reviews 2014, Issue 5. Art. No.: CD010681. DOI: 10.1002/14651858.CD010681.pub2.

Copyright @ 2014 The Cochrane Collaboration. Published by John Wiley \& Sons, Ltd.

\section{A B S T R A C T}

\section{Background}

Approximately $13 \%$ of women diagnosed with endometrial cancer present with advanced stage disease (International Federation of Gynecology and Obstetrics (FIGO) stage III/IV). The standard treatment of advanced endometrial cancer consists of cytoreductive surgery followed by radiation therapy, or chemotherapy, or both. There is currently little agreement about which adjuvant treatment is the safest and most effective.

\section{Objectives}

To evaluate the effectiveness and safety of adjuvant chemotherapy compared with radiotherapy or chemoradiation, and to determine which chemotherapy agents are most effective in women presenting with advanced endometrial cancer (FIGO stage III/IV).

\section{Search methods}

We searched the Cochrane Gynaecological Cancer Collaborative Review Group's Trial Register, the Cochrane Central Register of Controlled Trials (CENTRAL) (Issue 10 2013), MEDLINE and EMBASE up to November 2013. Also we searched electronic clinical trial registries for ongoing trials.

\section{Selection criteria}

Randomised controlled trials (RCTs) of adjuvant chemotherapy compared with radiotherapy or chemoradiation in women with FIGO stage III and IV endometrial cancer.

\section{Data collection and analysis}

Two review authors selected trials, extracted data, and assessed trials for risk of bias. Where necessary, we contacted trial investigators for relevant, unpublished data. We pooled data using the random-effects model in Review Manager (RevMan) software.

\section{Main results}

We included four multicentre RCTs involving 1269 women with primary FIGO stage III/IV endometrial cancer. We considered the trials to be at low to moderate risk of bias. All participants received primary cytoreductive surgery. Two trials, evaluating 620 women ( $83 \%$ stage III, $17 \%$ stage IV), compared adjuvant chemotherapy with adjuvant radiotherapy; one trial evaluating 552 women ( $88 \%$ stage III, $12 \%$ stage IV) compared two chemotherapy regimens (cisplatin/doxorubicin/paclitaxel (CDP) versus cisplatin/doxorubicin (CD) treatment) in women who had all undergone adjuvant radiotherapy; and one trial contributed no data. 
Overall survival (OS) and progression-free survival (PFS) was longer with adjuvant chemotherapy compared with adjuvant radiotherapy (OS: hazard ratio (HR) $0.75,95 \%$ confidence interval $(\mathrm{Cl}) 0.57$ to $0.99, \mathrm{I}^{2}=22 \%$; and PFS: $\mathrm{HR} 0.74,95 \% \mathrm{Cl} 0.59$ to $0.92, \mathrm{I}^{2}=0 \%$ ). Sensitivity analysis using adjusted and unadjusted OS data, gave similar results. In subgroup analyses, the effects on survival in favour of chemotherapy were not different for stage III and IV, or stage IIIA and IIIC (tests for subgroup differences were not significant and I ${ }^{2}=$ $0 \%$ ). This evidence was of moderate quality. Data from one trial showed that women receiving adjuvant chemotherapy were more likely to experience haematological and neurological adverse events and alopecia, and more likely to discontinue treatment (33/194 versus 6/202; RR 5.73, $95 \% \mathrm{Cl} 2.45$ to 13.36), than those receiving adjuvant radiotherapy. There was no statistically significant difference in treatmentrelated deaths between the chemotherapy and radiotherapy treatment arms (8/309 versus 5/311; Risk Ratio (RR) $1.67,95 \% \mathrm{Cl} 0.55$ to 5.00$)$.

There was no clear difference in PFS between intervention groups in the one trial that compared CDP versus CD (552 women; HR 0.90, $95 \% \mathrm{Cl} 0.69$ to 1.17 ). We considered this evidence to be of moderate quality. Mature OS data from this trial were not yet available. Severe haematological and neurological adverse events occurred more frequently with CDP than CD.

We found no trials to include of adjuvant chemotherapy versus chemoradiation in advanced endometrial cancer; however we identified one ongoing trial of this comparison.

\section{Authors' conclusions}

There is moderate quality evidence that chemotherapy increases survival time after primary surgery by approximately $25 \%$ relative to radiotherapy in stage III and IV endometrial cancer. There is limited evidence that it is associated with more adverse effects. There is some uncertainty as to whether triplet regimens offer similar survival benefits over doublet regimens in the long-term. Further research is needed to determine which chemotherapy regimen(s) are the most effective and least toxic, and whether the addition of radiotherapy further improves outcomes. A large trial evaluating the benefits and risks of adjuvant chemoradiation versus chemotherapy in advanced endometrial cancer is ongoing.

\section{PLAIN LANGUAGESUMMARY}

\section{Chemotherapy after surgery for stage III and IV endometrial cancer}

The issue: Advanced endometrial cancer (FIGO stage III and IV) is cancer of the womb which has spread beyond the womb to the ovaries, vagina, other adjacent tissues, draining lymph nodes, or other organs. Women are usually treated by surgery to remove as much of the tumour as possible. They are then offered adjuvant (meaning 'added') radiotherapy (high energy x-rays and other rays that destroy cancer cells), or chemotherapy (anti-cancer drugs), or both. There is uncertainty as to which treatment (radio- or chemotherapy or both) after surgery has the greatest effect on survival, and which anti-cancer drugs work best.

The aim of the review: We aimed to determine whether chemotherapy after surgery is effective compared to radiotherapy, in women with advanced cancer of the womb.

How was the review conducted? We searched the literature from 1966 to November 2013 for relevant randomised controlled trials (RCTs). We included four RCTs which were at low to moderate risk of bias and involved 1269 women. We wrote to the investigators of three trials for unpublished data. Three of the four trials compared similar interventions (chemotherapy versus radiotherapy after surgery). We pooled survival data (including the unpublished data) from two trials and await unpublished data for the third trial. The fourth trial compared two types of chemotherapy treatments after all women had received surgery and radiotherapy.

What are the main findings? Women who received chemotherapy after surgery (starting within eight weeks of surgery) survived approximately $25 \%$ longer than those receiving radiotherapy after surgery. Assuming that $60 \%$ of women with stage III endometrial cancer usually survive at least five years after surgery and radiotherapy, this would increase to $75 \%$ if they receive surgery and chemotherapy instead, depending on other risk factors, such as age. The risk of death which might have been caused by treatment was low with both chemotherapy and radiotherapy but we could not be sure if one was more harmful than the other. Chemotherapy may be associated with more side-effects (low blood counts, nerve damage and hair loss) compared with radiotherapy.

In the trial that compared two different chemotherapy treatments, there was no clear evidence that using three anti-cancer drugs was better than using two. However, the final overall survival results of this trial have not yet been reported. Severe side-effects were much more common in women treated with three anti-cancer drugs than two drugs.

What are the conclusions? Chemotherapy appears to be more effective than radiotherapy after surgery for women with stage III and IV endometrial cancer but may cause more side-effects. More research is needed to determine whether the addition of radiotherapy to chemotherapy improves outcomes and which anti-cancer drugs are best. 


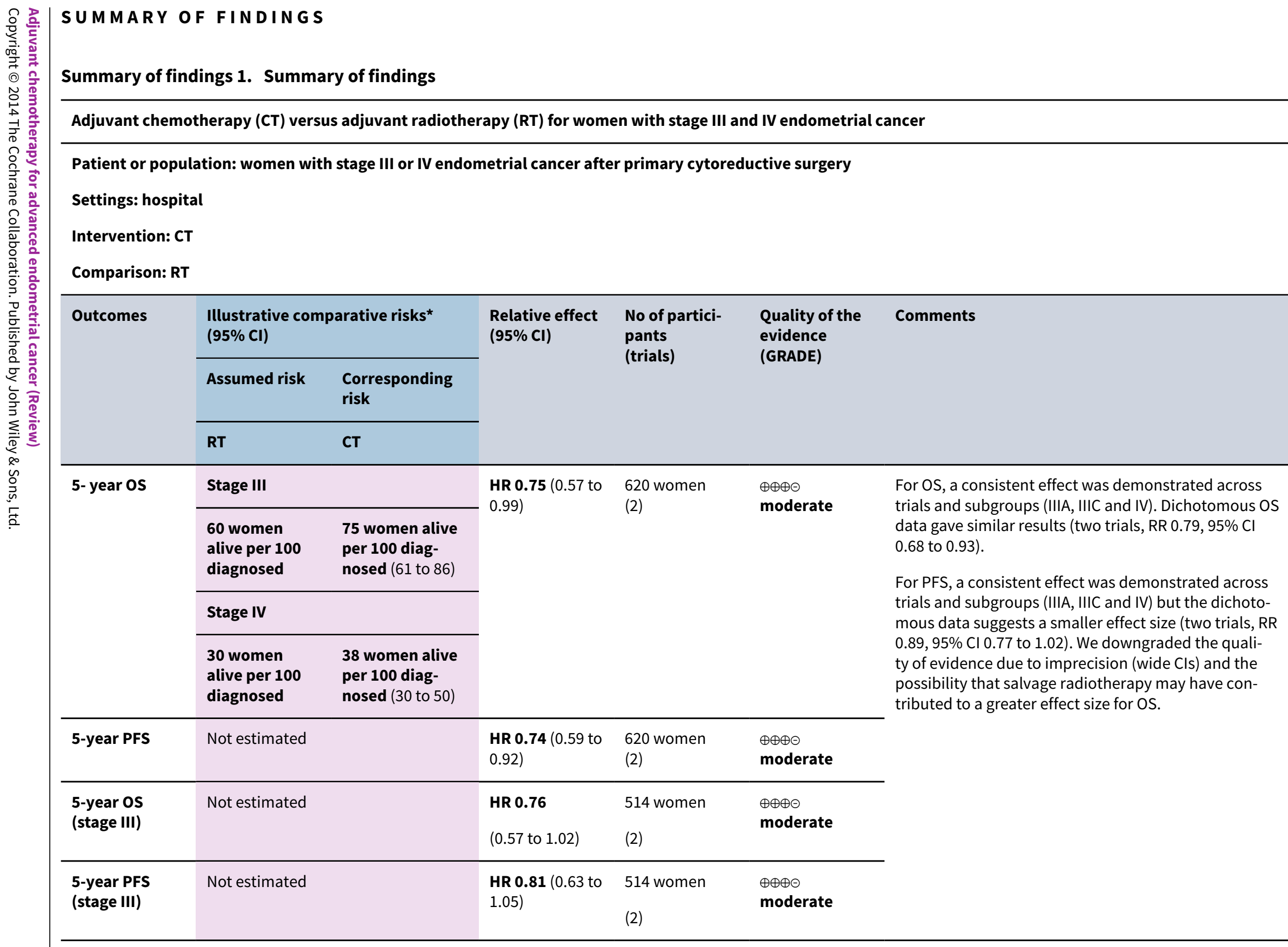


*The assumed risk is based on SEER survival data (SEER 2007). Use of these data assumes that the adjuvant treatment of choice from 1988 to 2001 was radiotherapy. Assumed risk varies depending on other risk factors, such as age and histology.

The corresponding risk (and its $95 \% \mathrm{Cl}$ ) is based on the assumed risk in the comparison group and the relative effect of the intervention (and its $95 \% \mathrm{Cl}$ ). CI: Confidence interval; HR: Hazard ratio; OS: Overall survival; PFS: Progression-free survival; CT: chemotherapy; RT: radiotherapy.

GRADE Working Group grades of evidence

High quality: Further research is very unlikely to change our confidence in the estimate of effect.

Moderate quality: Further research is likely to have an important impact on our confidence in the estimate of effect and may change the estimate.

Low quality: Further research is very likely to have an important impact on our confidence in the estimate of effect and is likely to change the estimate.

Very low quality: We are very uncertain about the estimate.

\section{Summary of findings 2 . Summary of findings}

\section{Adjuvant cisplatin/doxorubicin/paclitaxel (CDP) compared with cisplatin/doxorubicin (CD) for women with advanced (stage III/IV) endometrial cancer}

Patient or population: women with advanced (stage III/IV) endometrial cancer after surgery and radiotherapy

Settings: hospital

Intervention: CDP

Comparison: $C D$

\begin{tabular}{lllll}
\hline Outcomes & $\begin{array}{l}\text { Relative effect } \\
\text { (95\% CI) }\end{array}$ & $\begin{array}{l}\text { No of participants } \\
\text { (trials) }\end{array}$ & $\begin{array}{l}\text { Quality of the evi- } \\
\text { dence } \\
\text { (GRADE) }\end{array}$ & Comments \\
\hline PFS (stage III/IV) & HR $0.90(0.69$ to 1.17$)$ & $\begin{array}{l}552 \\
(1)\end{array}$ & $\begin{array}{l}\oplus \oplus \oplus \ominus \\
\text { moderate }\end{array}$ & $\begin{array}{l}\text { We considered this evidence high quality but downgraded it to } \\
\text { moderate, as mature OS data has not yet been published, there- } \\
\text { fore we cannot exclude other differences in survival risks/benefits. }\end{array}$ \\
\hline
\end{tabular}

CI: Confidence interval; HR: Hazard ratio; PFS: Progression-free survival; CDP: cisplatin/doxorubicin/paclitaxel; CD: cisplatin/doxorubicin.

GRADE Working Group grades of evidence

High quality: Further research is very unlikely to change our confidence in the estimate of effect.

Moderate quality: Further research is likely to have an important impact on our confidence in the estimate of effect and may change the estimate.

Low quality: Further research is very likely to have an important impact on our confidence in the estimate of effect and is likely to change the estimate.

Very low quality: We are very uncertain about the estimate. 


\section{B A C K G R O U N D}

\section{Description of the condition}

Endometrial cancer (cancer of the lining of the uterus) is the fifth most common cancer in women, accounting for an estimated 320,000 new cases globally each year (IARC 2013). A woman's risk of developing endometrial cancer by the age of 75 is estimated to range from $0.6 \%$ in developing countries to $1.6 \%$ in developed countries (Jemal 2011). Risk factors include age, obesity, diabetes mellitus, nulliparity, late menopause, unopposed oestrogen intake or oestrogen-producing tumours, a history of breast cancer and the use of tamoxifen (Berek 2010). Although the incidence and mortality rates of several other cancers have plateaued or decreased over the last decade, the incidence of endometrial cancer has been rising (Jemal 2008). In the United Kingdom, the number of women with endometrial cancer has increased by over 40\% since 1993 (Evans 2011).

Endometrial cancer is predominantly a disease of post-menopausal women and most common in women over 50 years of age. Only $10 \%$ to $15 \%$ of women presenting with symptoms actually harbour endometrial cancer, and the incidence of endometrial cancer in women with perimenopausal bleeding may be less than $2 \%$ (Dubinsky 2004). Over $70 \%$ of women with endometrial cancer present with International Federation of Gynecology and Obstetrics (FIGO) stage I disease (Creasman 2006), which is associated with a five-year survival rate of greater than $90 \%$ (Creasman 2006). Only a small proportion of women (13\%) present with advanced disease, with five-year survival rates of around $60 \%$ and $30 \%$ for stage III and IV, respectively, which decrease with advancing age (SEER 2007).

The standard surgical treatment of women with endometrial cancer includes the removal of the uterus, both fallopian tubes and ovaries (total hysterectomy and bilateral salpingo-oophorectomy), with or without lymphadenectomy (Colombo 2011). Although pelvic and paraaortic lymphadenectomy is not recommended in stage I disease, in other stages it is valuable in determining a woman's prognosis and in tailoring additional treatment (Colombo 2011). After surgery, a woman may be offered radiation therapy, or platinum-based chemotherapy, or both, depending on her risk factors (including advanced age, grade 3, lymphovascular space invasion and bulky disease) and the stage of the disease (Colombo 2011).

Treatment of advanced disease (Stage III and IV) is individualized and usually involves a combination of cytoreductive surgery (CRS), radiotherapy, or chemotherapy (Berek 2010), or both. Complete cytoreduction, leaving no gross residual disease, is the aim of CRS and is associated with a superior overall survival compared with sub-optimal cytoreduction (Barlin 2010). Treatment of metastatic disease is dictated by the site of the metastases and the associated symptoms (Berek 2010).

If the tumour is not amenable to surgery, (non-adjuvant) chemotherapy may be given with the aim of palliating symptoms, improving quality of life (QoL), delaying progression of disease and extending survival (Humber 2007). According to a recent Cochrane review of non-adjuvant chemotherapy for advanced, recurrent or metastatic disease, the use of 'more chemotherapy' compared with 'less chemotherapy' is associated with a longer survival (Vale 2012). Current evidence does not support the use of hormonal therapy in endometrial cancer at any stage (Kokka 2010; Martin-Hirsch 2011).

\section{Description of the intervention}

Until recently, endometrial cancer was considered a relatively chemoresistant tumour and, as such, radiotherapy was the preferred adjuvant treatment, with chemotherapy reserved as salvage therapy for progressive disease (McMeekin 2009). However, it is now known that doxorubicin, platinum drugs and paclitaxel all have activity against endometrial cancer (McMeekin 2009). Although adjuvant chemotherapy regimens usually consist of a platinum drug combined with doxorubicin or paclitaxel, the optimal drug combination/regimen is yet to be established. In addition, the relative survival effects of adjuvant chemotherapy, or chemoradiation, or both, for advanced disease have not been elucidated.

\section{Why it is important to do this review}

In a review of adjuvant chemotherapy in endometrial cancer at any stage, Johnson 2011 concluded that platinum-based chemotherapy may be used as an alternative or addition to radiotherapy. However, there is little agreement on what should be the standard adjuvant treatment of stage III and IV endometrial cancer. The European Society of Medical Oncologists (ESMO) recommends adjuvant chemotherapy for stage III and IV disease, with sequential radiotherapy if lymph nodes are positive (Colombo 2011). In this systematic review, we aimed to evaluate the evidence from RCTs regarding the benefits and risks of adjuvant chemotherapy for advanced (stage III and IV) disease.

\section{OB JECTIVES}

In women with primary advanced endometrial cancer (FIGO stage III/IV):

1. To evaluate the effectiveness and safety of adjuvant chemotherapy compared with adjuvant radiotherapy or chemoradiation;

2. To determine which type(s) of chemotherapy agents are most effective.

\section{METHODS}

\section{Criteria for considering studies for this review}

\section{Types of studies}

Randomised controlled trials (RCTs).

\section{Types of participants}

Adult women (18 years of age or older) diagnosed with advanced endometrial cancer (FIGO stage III/IV) who underwent cytoreductive surgery (CRS) as part of the management of their disease.

\section{Types of interventions}

For comparison of treatment modalities:

1. Adjuvant chemotherapy versus adjuvant radiotherapy;

2. Adjuvant chemotherapy versus a different adjuvant chemotherapy regimen;

3. Adjuvant chemotherapy versus adjuvant chemoradiation 


\section{Types of outcome measures}

\section{Primary outcomes}

- Overall survival (death from all causes; OS) from the time that women were enrolled in the trial.

\section{Secondary outcomes}

- Progression-free survival (PFS);

- Quality of life (QoL);

- Adverse events (CTCAE 2006), including:

- Direct surgical morbidity (e.g. death within 30 days; injury to bladder, ureter, vascular, small bowel or colon), presence and complications of adhesions, febrile morbidity, intestinal obstruction, haematoma, local infection).

- Surgically-related systemic morbidity (chest infection, thromboembolic events, cardiac events, cerebrovascular accidents).

- Recovery events: delayed discharge, unscheduled readmission.

- Adjuvant therapy toxicity.

- Treatment discontinuation due to refusal or toxicity.

We extracted and grouped data on the number of participants with severe chemotherapeutic and radiotherapeutic toxicity (CTCAE 2006 Grade 3-5), including the following:

- haematological (leucopaenia, anaemia, thrombocytopenia, neutropenia, haemorrhage);

- gastrointestinal (nausea, vomiting, anorexia, diarrhoea, liver, proctitis);

- genitourinary;

- skin (stomatitis, mucositis, alopecia, allergy);

- neurological (peripheral and central); and

- pulmonary.

\section{Search methods for identification of studies}

We sought publications in all languages and performed translations if necessary.

\section{Electronic searches}

See the Cochrane Gynaecological Cancer Group methods used in reviews.

We searched the following electronic databases until November 2013:

- The Cochrane Gynaecological Cancer Collaborative Review Group's Trial Register;

- Cochrane Central Register of Controlled Trials (CENTRAL), Issue 10, 2013;

- MEDLINE to November 2013;

- EMBASE to November 2013.

We presented the MEDLINE, EMBASE and CENTRAL search strategies based on terms related to the review topic in Appendix 1 , Appendix 2 and Appendix 3, respectively.
We identified all relevant articles on PubMed, and by using the 'related articles' feature, we performed a further search for newly published articles.

\section{Searching other resources}

We searched www.controlled-trials.com/rct, www.clinicaltrials.gov, www.cancer.gov/clinicaltrials and Gynaecologic Oncologists of Canada (http://www.g-o-c.org) for ongoing trials. We handsearched reference lists of included trials and used the 'related citations' feature of PubMed to identify any other relevant trials.

\section{Data collection and analysis}

\section{Selection of studies}

We downloaded all titles and abstracts retrieved by electronic searching to the reference management database ENDNOTE (ENDNOTE X7.0.2) and removed duplicates. Two review authors (TAL, KG) examined the remaining references independently. We excluded trials that did not meet the inclusion criteria and obtained full text of potentially relevant references. Two review authors (KG, TAL) assessed the eligibility of retrieved papers independently. We resolved disagreements by discussion between two review authors (KG, TAL) or by appeal to a third review author (AB). We documented reasons for exclusion.

\section{Data extraction and management}

For included trials, we extracted data as recommended in Chapter 7 of the Cochrane Handbook for Systematic Reviews of Interventions (Higgins 2011), including data on the following:

- Author, year of publication and journal citation (including language);

- Country;

- Setting;

- Inclusion and exclusion criteria;

- Trial design, methodology;

- Trial population:
- Total number enrolled
- Participant characteristics
- Age
- Comorbidities;

- Endometrial cancer details at diagnosis:
- FIGO stage
- Histological cell type
- Tumour grade
- Extent of disease
- Disease-free interval
- Number of recurrences;

- Total number of intervention groups; 
- Intervention details:

- Treatment modalities

- Details of surgery

- Type of surgeon (gynaeoncologist, gynaecologist, general surgeon)

- Experience of surgeon

- Details of chemotherapy, or radiotherapy, or both;

- Dose

- Cycle length

- Combination

- Details of best supportive care;

- Risk of bias in trial (see below);

- Duration of follow-up;

- Outcomes-OS, PFS, QoL, adverse events and treatment discontinuation due to toxicity or refusal

- For each outcome: outcome definition (with diagnostic criteria if relevant)

- Unit of measurement (if relevant)

- For scales: upper and lower limits and whether high or low score is good

- Results: number of participants allocated to each intervention group

- For each outcome of interest: sample size and missing participants.

We extracted data on outcomes as below:

- For time-to-event data, we extracted the log of the hazard ratio $[\log (\mathrm{HR})]$ and its standard error (SE) from trial reports;

- For dichotomous outcomes (adverse events), we extracted the number of participants in each group who experienced the outcome of interest and the number of participants assessed at endpoint to estimate a risk ratio (RR).

Where possible, we extracted all data relevant to an intention-totreat (ITT) analysis in which participants were analysed in groups to which they were assigned. We recorded the time points at which outcomes were collected and reported. Two review authors (KG, TAL) extracted data independently using a pre-designed data collection form. We resolved differences between review authors by discussion or by appeal to a third review author (AB) when necessary.

\section{Assessment of risk of bias in included studies}

We assessed the risk of bias of included RCTs in accordance with guidelines in the Cochrane Handbook for Systematic Reviews of Interventions using the Cochrane Collaboration's tool and the criteria specified in Chapter 8 (Higgins 2011). This included assessment of:

- sequence generation;

- allocation concealment;

- blinding (restricted to blinding of outcome assessors as not possible to blind participants and health care providers to surgical intervention);

- incomplete outcome data:

- We recorded the proportions of participants whose outcomes were not reported at the end of the trial. We coded the satisfactory level of loss to follow-up for each outcome as follows:

- Yes, if fewer than $20 \%$ of participants were lost to followup and reasons for loss to follow-up were similar in both treatment arms;

- No, if more than $20 \%$ of participants were lost to followup or reasons for loss to follow-up were different between treatment arms; and

- Unclear, if loss to follow-up was not reported.

- selective reporting of outcomes; and

- other possible sources of bias.

Two review authors (KG, TAL) applied the risk of bias tool independently and we resolved differences by discussion or by appeal to a third reviewer (AB). We summarised results in a risk of bias summary (Figure 1 ) and interpreted results of meta-analyses in light of the findings with respect to risk of bias. 
Figure 1. Risk of bias summary: review authors' judgements about each risk of bias item for each included trial.

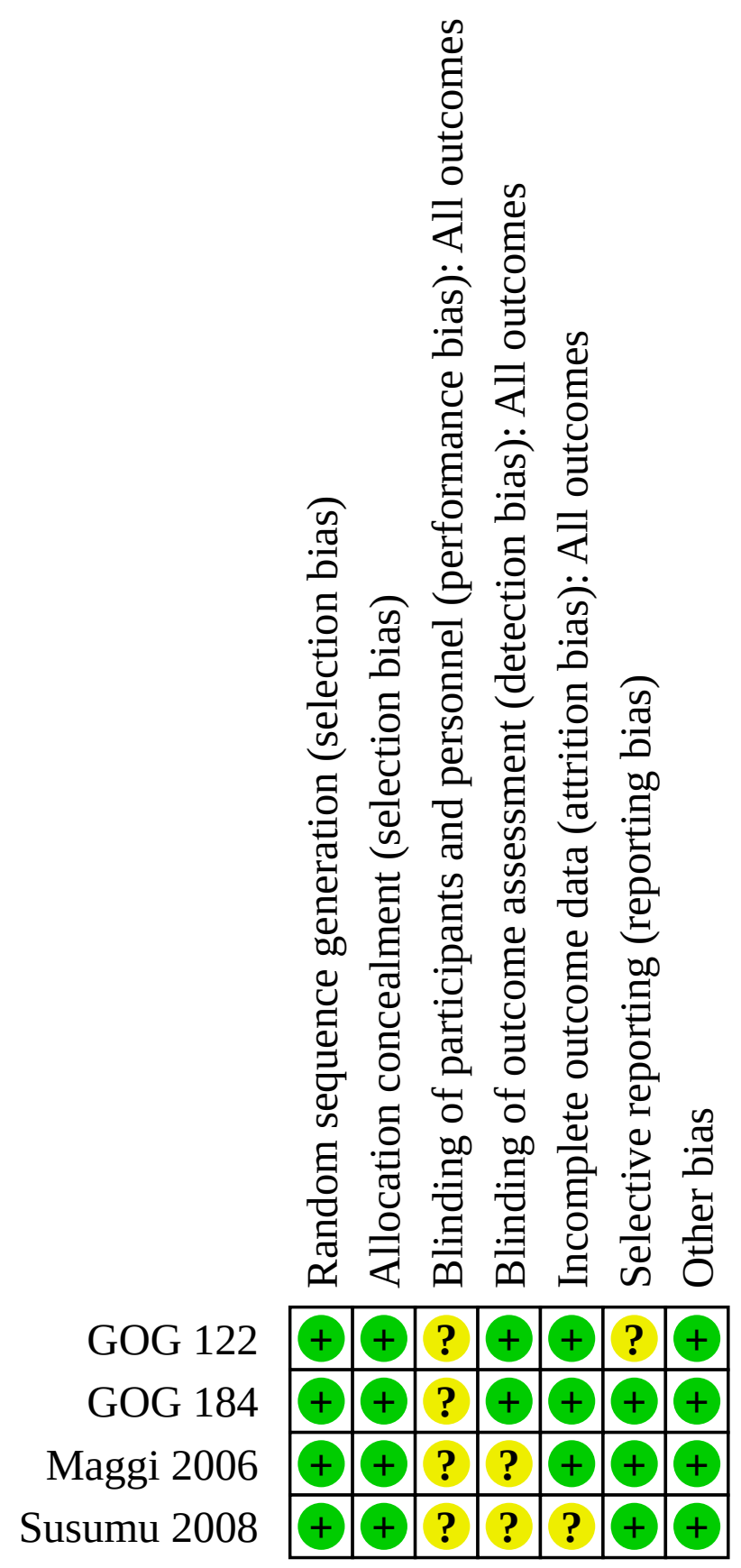

\section{Measures of treatment effect}

We used the following measures of the effect of treatment:
- For time-to-event data, we used the hazard ratio (HR) to compare the risk of death or disease progression in the treatment group with that in the control group;

- For dichotomous outcomes (adverse events), we used the risk ratio (RR). 


\section{Dealing with missing data}

We did not impute missing outcome data for any of the outcomes. We contacted trial authors if data were missing or if only imputed data were reported to request data on outcomes only among participants who were assessed.

\section{Assessment of heterogeneity}

We assessed statistical heterogeneity between trials by visual inspection of forest plots, by estimation of the percentage heterogeneity between trials that cannot be ascribed to sampling variation (Higgins 2003) and by a formal statistical test of the significance of the heterogeneity (Deeks 2001). We considered statistical heterogeneity between trials to be substantial if, following meta-analysis, $\mathrm{I}^{2}$ was greater than $30 \%$ and either $\mathrm{T}^{2}$ is greater than zero, or there was a low $\mathrm{P}$ value $(<0.10)$ in the $\mathrm{Chi}^{2}$ test for heterogeneity. We used the random-effects model for all metaanalyses.

\section{Assessment of reporting biases}

There was an insufficient number of trials for an adequate assessment of small trial biases such as publication bias.

\section{Data synthesis}

We pooled the results in meta-analyses where possible using adjusted summary statistics and the random-effects model.

- For time-to-event data, we pooled HRs using the generic inverse variance facility of Review Manager (RevMan);
- For dichotomous outcomes, we pooled RRs.

\section{Subgroup analysis and investigation of heterogeneity}

We obtained unpublished data where possible and performed subgroup analysis according to stage for the comparison 'adjuvant chemotherapy versus adjuvant radiotherapy'. Where possible, we considered other risk factors such as age, stage, grade, histology, type of chemotherapy regimen used and length of follow-up to assess clinical heterogeneity. We performed exploratory metaanalyses of stage III sub-stages IIIA and IIIC. The sample size of the stage IIIB sub-stage was insufficient for meta-analysis.

\section{Sensitivity analysis}

Where possible, we performed sensitivity analysis using adjusted and unadjusted overall data for the primary outcomes. This was possible for overall survival only. In addition, we performed metaanalyses of dichotomous survival data for OS and PFS.

\section{RESULTS}

\section{Description of studies}

\section{Results of the search}

We identified 1473 citations, which reduced to 599 after we removed duplicates and irrelevant citations. We identified 57 records for screening, which resulted in 17 full text articles (pertaining to 13 trials) for classification (Figure 2). Following examination of the full text articles, we included four trials (seven reports) and excluded nine trials (ten reports). In addition, we identified two ongoing trials (GOG 0258; PORTEC-3). 
Figure 2. Study flow diagram.

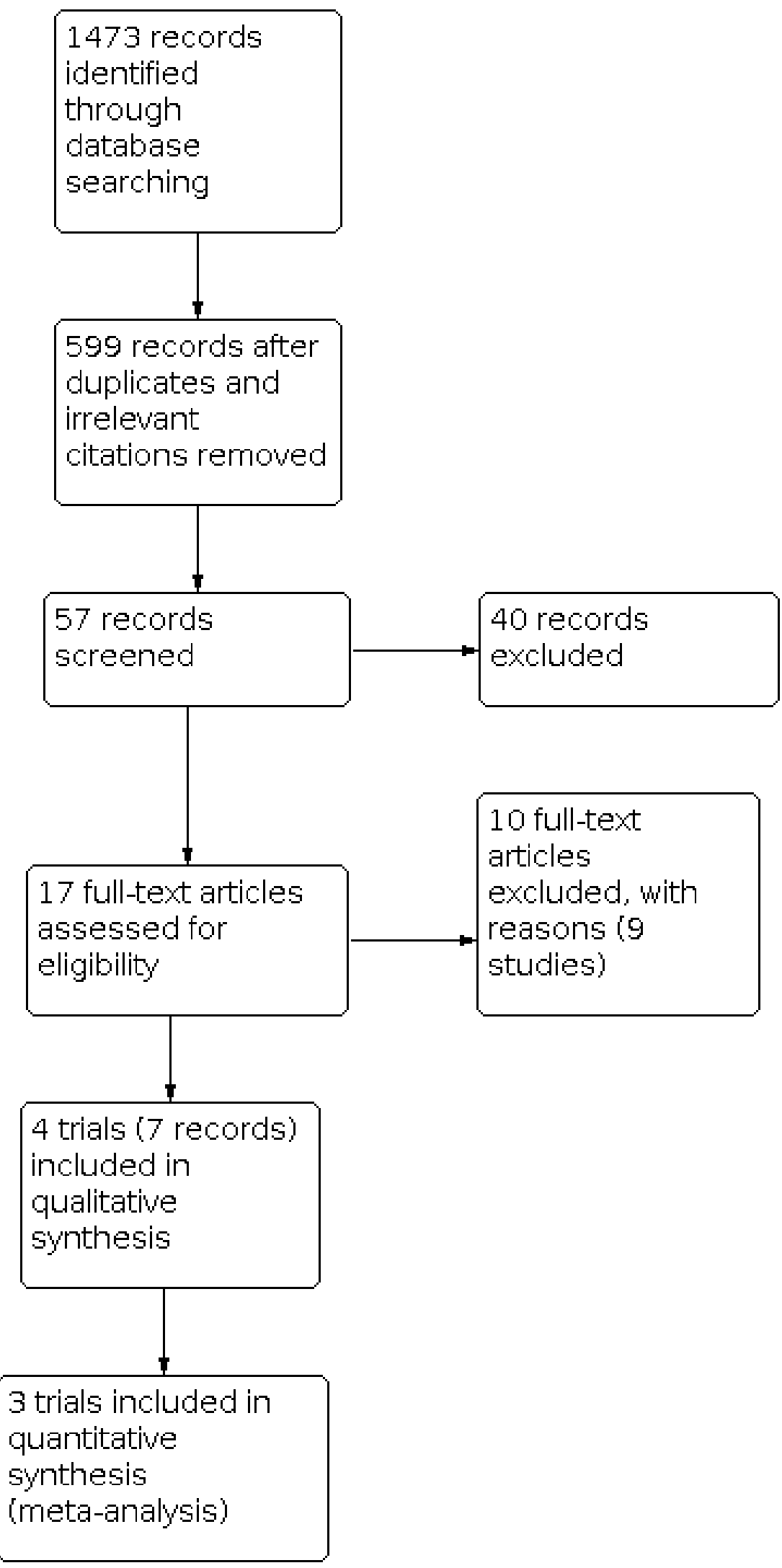




\section{Included studies}

We included four trials:

- GOG 122: a RCT of adjuvant chemotherapy versus whole body irradiation in women with stage III and IV endometrial cancer within eight weeks of CRS;

- GOG 184: a RCT comparing two different adjuvant chemotherapy regimens in women with stage III and IV endometrial cancer following CRS and radiotherapy;

- Maggi 2006: a RCT comparing adjuvant chemotherapy versus pelvic external beam radiotherapy in women with high-risk (stage IC G3 to III) endometrial cancer within 30 days of surgery. As this trial included a significant proportion of stage III patients (64\%), we requested separate stage III data from the investigators;

- Susumu 2008: a RCT comparing adjuvant chemotherapy versus pelvic external beam radiotherapy in women with high-risk (stage IC G3 to III) endometrial cancer within four weeks of surgery. As this trial comprised $25 \%$ of stage III patients, we requested separate stage III data from the investigators.

Both GOG 122 and GOG 184 were multicentre, parallel RCTs conducted in the USA. GOG 122 enrolled 422 women with FIGO stage III or IV endometrial cancer of any histology, of whom 396 were evaluable. Pre-randomisation CRS included total abdominal hysterectomy (TAH) and bilateral salpingo-oophorectomy (BSO), surgical staging and tumour resection to a maximum of $2 \mathrm{~cm}$ residual tumour at a single site. Women commenced adjuvant treatment within eight weeks of CRS. Participants' baseline characteristics were: $50 \%$ endometrioid tumours; $27 \%$ stage IV; $52 \%$ grade $3 ; 86 \%$ microscopic residual disease; $95 \%$ performance status $0-1$; and median age 63 years. Risk factors for poorer prognosis were slightly skewed in favour of the WAI arm and results were adjusted for these risk factors in the trial analyses. Median follow-up was 74 months overall. Outcomes assessed included OS, PFS, adverse events and QoL. GOG 122 compared QoL between intervention arms using the Fatigue Scale (FS), Assessment of Peripheral Neuropathy (APN), Functional Alterations due to Changes in Elimination (FACE) and Functional Assessment of Cancer Therapy - General (FACT-G). Baseline data were obtained for $317 / 396$ women $(80 \%)$ and " 70 to $80 \%$ " of living patients completed QoL assessments at three month and six month time points.

GOG 184 enrolled 586 women, of whom 552 were evaluated. Women were eligible if they had FIGO stage III or IV endometrial cancer of any histology, with disease limited to the pelvis and abdomen. Pre-randomisation treatment included CRS (at least a hysterectomy and BSO) and radiotherapy. The interventions compared were cisplatin, doxorubicin and paclitaxel versus cisplatin and doxorubicin, every three weeks for six cycles. After the results of GOG 122 were known, women with stage IV were no longer eligible as GOG 122 showed a statistically significant benefit in PFS with adjuvant chemotherapy compared with adjuvant radiotherapy in stage IV disease. Therefore, the proportion of stage IV women enrolled in this trial was less than in GOG 122. Baseline characteristics for GOG 184 were: $69 \%$ endometrioid tumours; $12 \%$ stage IV; $41 \%$ grade $3 ; 90 \%$ absent or microscopic residual disease; $99 \%$ performance status $0-1$; and median age 58 years. Median follow-up was 47 and 46 months for the trial arms, respectively. Outcomes assessed included recurrence -free survival (RFS) (three year), OS, loco-regional recurrence, distant recurrence, and adverse events. Peripheral neuropathy was measured using the Functional Assessment of Cancer Therapy - Neurotoxicity (FACT-N) at baseline, four weeks and six months after chemotherapy. The trial authors included women who completed follow-up assessments (422/552) in the analysis. Overall survival has not yet been reported for this trial and we were unable to obtain mature, unpublished data from the investigators.

Maggi 2006 was a multicentre, parallel RCT conducted in Italy. Maggi 2006 included women with stages IC G3 to III disease ( $N=$ 345). We obtained separate, unpublished stage III data ( $N=224)$ from the Maggi 2006 investigators, facilitating our inclusion of this trial. In Maggi 2006 randomisation was stratified by stage of disease, with approximately $26.5 \%$ stage I, $9 \%$ stage II and $64 \%$ stage III disease, therefore we included only the stage III data from this trial in our meta-analyses. The chemotherapy arm received cisplatin, doxorubicin and cyclophosphamide every 28 days for five cycles. Women commenced adjuvant treatment within 30 days of CRS. Overall baseline characteristics, which were similar for both intervention groups, were: $57 \%$ grade $3,72 \%$ myometrial invasion $>50 \%$, median age 62.5 years. All participants underwent CRS, $93 \%$ of whom had a TAH and BSO; however, the percentage with residual disease was not reported. Median follow-up was 95.5 months. Outcomes assessed included 3-, 5-, and 7-year OS, PFS and adverse events.

Susumu 2008 was a multicentre, parallel RCT conducted in Japan. Women with endometrial cancer FIGO stages IC to III were evaluated ( $\mathrm{N}=385$ analysed), including 97 women with stage III disease. Randomisation was not stratified by stage of disease. We requested separate data from the trial investigators for the stage III subgroup. The chemotherapy arm received cisplatin, doxorubicin and cyclophosphamide every 28 days for three to seven cycles. Women commenced adjuvant treatment within four weeks of CRS. Overall baseline characteristics were similar for both intervention groups: all women had endometrioid histology and no residual disease, $53 \%$ had grade 3 lesions, $100 \%$ had myometrial invasion $>50 \%$, and the mean age was 59 years. Pelvic lymphadenopathy was performed in $96 \%$ and paraaortic lymphadenopathy was performed in $29 \%$ of participants. Median follow-up was approximately 60 months and outcomes assessed were five-year OS, PFS and toxicity.

\section{Excluded studies}

We excluded nine studies for the following reasons:

- Study intervention was not eligible (non-adjuvant chemotherapy) (Aapro 2003; Fleming 2004a; Fleming 2004b; Gallion 2003; Nomura 2011);

- Study comparison was not eligible (radiotherapy versus chemoradiation) (Hogberg 2010; Kuoppala 2008);

- Study was not a RCT (Mustea 2013);

- Study was conducted in women with uterine sarcomas not endometrial carcinoma (Wolfson 2007).

\section{Risk of bias in included studies}

Included trials were of high quality and we considered them to be at low risk of bias. We have summarised the risk of bias in the included trials in Figure 1. Also, we have listed details with support for judgement in the 'Risk of Bias' section of the Characteristics of included studies tables. 
Figure 4. Forest plot of comparison: 1 Chemotherapy versus radiotherapy, outcome: 1.6 PFS (Stage III/IV).

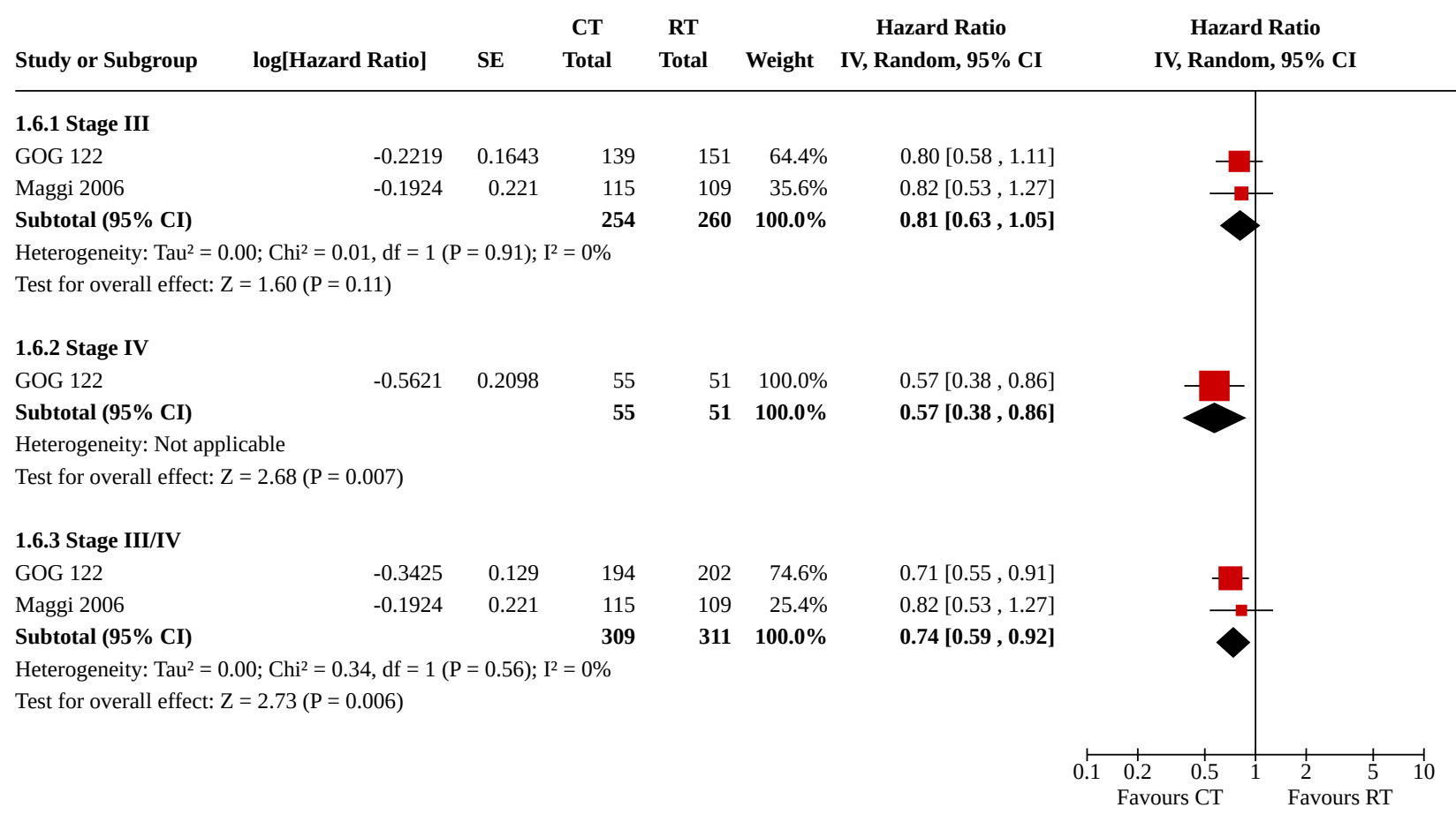

In exploratory meta-analyses (Analysis 1.8) of sub-stages IIIA (HR $0.66,95 \% \mathrm{Cl} 0.43$ to 1.01 , two trials, 234 women; $I^{2}=0 \%$ ); and IIIC (HR $0.86,95 \% \mathrm{Cl} 0.61$ to 1.21 , two trials, 265 women; $\left.\right|^{2}=0 \%$ ) (IIIB sample was too small for analysis), there was no statistically significant difference in effect (test for subgroup differences: $\mathrm{Chi}^{2}=0.92, \mathrm{df}=2$ $(P=0.34), I^{2}=0 \%$; Analysis 1.8).

\section{Severe adverse events}

GOG 122 reported significantly more haematological and neurological SAEs with adjuvant chemotherapy compared with the adjuvant radiotherapy, as well as significantly more alopecia, and significantly more women discontinued treatment due to toxicity in the chemotherapy arm (Analysis 1.11). There was no statistically significant difference in treatment related deaths (RR $1.67,95 \% \mathrm{Cl}$ 0.55 to 5.00 , two trials, 620 women; Analysis 1.12).

Separate SAE data for Maggi 2006 and Susumu 2008 were not available for stage III participants only. Overall, grade $3 / 4$ neutropenia occurred in 35\% of women in the chemotherapy arm of Maggi 2006. Gastrointestinal toxicity (G3/4) occurred in $11 \%$ and $16 \%$ of women in the chemotherapy and radiotherapy arms, respectively. Susumu 2008 reported total G3/G4 toxicities as 9/192 (4.7\%) for the chemotherapy arm and 3/193 (1.6\%) for the radiotherapy arm. Bowel-obstruction was the main complication in the radiotherapy group whereas myelosuppression was the main complication in the chemotherapy group. Maggi 2006 and Susumu 2008 had no treatment-related deaths.

\section{Quality of life (QoL)}

At three months post-treatment, APN scores were significantly worse in the chemotherapy arm compared with radiotherapy $(\mathrm{P}<$ 0.001 ), and FACE scores were significantly worse in the radiotherapy arm compared with chemotherapy $(P=0.004)$. FS scores were significantly worse in the radiotherapy arm at end of treatment (EOT) $(P<0.001)$ compared with the chemotherapy arm, There were no significantly differences in FACT-G scores at EOT, three months or six months from baseline.

\section{B. Comparisons between chemotherapy regimens}

One trial, including 552 women (88\% stage III, 12\% stage IV), compared two different chemotherapy regimens (cisplatin/ doxorubin/paclitaxel (CDP) versus cisplatin/doxorubicin (CD) treatment) in participants who had received both CRS and adjuvant radiotherapy. There was no statistically significant difference in PFS between treatment arms in this trial (HR $0.90,95 \% \mathrm{Cl} 0.69$ to 1.17, one trial, 552 women; Analysis 2.2); however, participants in the CDP arm experienced significantly more severe haematological and neurological adverse events and were possibly more likely to discontinue treatment (Analysis 2.4; not statistically significant). Patient reported FACT-N scores corresponded with clinician scores and were significantly worse in the triplet regimen group $(P<0.001)$ at the four week and six month time points.

\section{Comparison between adjuvant chemotherapy and chemoradiation}

We identified one ongoing RCT of this intervention (GOG 0258) and will include the results in this review when they are available.

\section{DISCUSSION}

\section{Summary of main results}

Women with advanced endometrial cancer (FIGO stage III and IV) survived approximately $25 \%$ longer if they received chemotherapy after primary surgery, compared with radiotherapy $(95 \% \mathrm{Cl} 1 \%$ to $43 \%$; see Summary of findings 1 ). PFS was $26 \%$ longer with adjuvant chemotherapy compared with radiotherapy $(95 \% \mathrm{Cl} 8 \%$ 
to $41 \%)$. In subgroup analyses, the effects on survival in favour of chemotherapy were not different for stage III and IV, or stage IIIA and IIIC (tests for subgroup differences were not significant).

The four included trials used three different platinum-based chemotherapy drug combinations (GOG 122: cisplatin/doxorubicin (CD); Maggi 2006 and Susumu 2008: cisplatin/doxorubicin/ cyclophosphamide (CDC); and GOG 184: CD plus paclitaxel (CDP) versus $(D)$. Drug doses and median number of cycles differed between the trials, with $50 \%$ or more participants receiving 3,5 and 8 cycles in Susumu 2008, Maggi 2006 and GOG 122, respectively. Susumu 2008 reported correspondingly fewer severe adverse events in the chemotherapy arm compared with the other two trials. There was no statistically significant difference in PFS when CDP was compared with CD in GOG 184, the only included trial that compared two adjuvant chemotherapy regimens. We are awaiting mature $O S$ results from this trial.

\section{Overall completeness and applicability of evidence}

We consider this evidence to be applicable to most women with stage III and IV disease, when adjuvant chemotherapy is started within eight weeks of primary surgery. However, the majority of women taking part in these trials had a high performance status, which does not reflect the performance status of all women with advanced endometrial cancer, particularly the elderly, who are more susceptible to toxicity from chemotherapeutic agents. We were unable to perform subgroup analyses according to age or other risk factors, due to insufficient data. Therefore, it is likely that the extent of the survival benefit of adjuvant chemotherapy compared with adjuvant radiotherapy will vary depending on these additional risk factors, and that individualised treatment of these women will be needed. In addition, women with stage IIIB were poorly represented in these data. It is possible that women with stage IIIB (vaginal spread) would receive more benefit from adjuvant radiotherapy or chemoradiation. Further research is needed to determine whether and in whom the addition of radiotherapy will be beneficial.

Further research is needed to determine which adjuvant chemotherapy regimen gives the best results. The chemotherapy arm in Susumu 2008 experienced less G3/G4 toxicity compared with the other trials in this review which may be attributable to fewer cycles (median $=3$ ) or the lower doxorubicin dose administered (40 $\mathrm{mg} / \mathrm{m}^{2}$ ). We await the final results of GOG 184 , as well as the results of a large trial of chemoradiation and adjuvant chemotherapy versus adjuvant chemotherapy only in advanced disease (GOG 0258). In addition, the results of PORTEC-3, a trial of adjuvant chemoradiation versus radiotherapy that includes women with stage III disease will contribute to the growing body of evidence on the management of advanced endometrial cancer.

\section{Quality of the evidence}

The overall risk of bias of included trials was low to moderate. Previously, GOG 122 has been criticised for reporting adjusted data (Johnson 2011), therefore we performed sensitivity analyses using adjusted and unadjusted data from GOG 122 and Maggi 2006 for overall survival. For the former we used the estimate in Johnson 2011; for the latter we obtained these from the principal investigators. We used the random-effects model for survival meta-analyses even though statistical heterogeneity was minimal. The unadjusted data for OS gave the same point estimate as adjusted data, with a narrower $\mathrm{Cl}$ and no statistical heterogeneity. We therefore consider the evidence relating to survival for the comparison adjuvant chemotherapy versus radiotherapy to be consistent and reasonably precise, with minimal heterogeneity. Since the survival effect using dichotomous data was greater for OS than for PFS, it has been suggested that the overall survival benefit in favour of chemotherapy may have been impacted by subsequent salvage radiotherapy. Therefore we downgraded the evidence to moderate quality. We also consider the evidence for the comparison of the CDP versus CD regimens to be of moderate quality, pending assessment of the final survival results.

\section{Potential biases in the review process}

We obtained and included unpublished data from Maggi 2006, which included a significant proportion of stage III patients (64\%). We also requested stage III data from the investigators of the Susumu 2008 trial, comprising $25 \%$ of the sample size of this trial. The latter trial included women with stages $1 \mathrm{C}$ to IIIC but did not stratify randomisation according to stage of disease; they reported no significant differences in survival between women in the adjuvant chemotherapy and radiotherapy groups overall. However, in subgroup analyses of 120 women with high-intermediate risk disease, chemotherapy was associated with a significantly improved survival (OS and PFS) compared with the radiotherapy. In further ad-hoc analyses of 75 of these women considered to be 'high risk' (stage IIIB/C and IIIA with additional risk factors), there was no significant difference in survival between the trial arms. Due to concerns about bias, we decided to await separate stage III data (97 women) as the paper lacked sufficient detail about this subgroup (e.g. the number of high risk women evaluable in each group). We intend to include these requested data in the review when they become available; however, based on the published data from this trial and the small numbers involved, we do not expect that these data will significantly alter the review findings.

\section{Agreements and disagreements with other studies or reviews}

Johnson 2011 concluded that adjuvant chemotherapy could be used as an alternative, or addition to, adjuvant radiotherapy in women with endometrial cancer. The review combined data from studies of adjuvant chemotherapy or chemoradiation compared to radiotherapy for any stage of endometrial cancer or uterine sarcoma. Thus, there was substantial clinical heterogeneity in the interventions and the participants included in Johnson 2011. Johnson 2011 also included trials conducted mainly in women with endometrial cancer stages III and IV (GOG 122; Maggi 2006), comprising a significant proportion of these pooled data (> 50\%) and having a significant impact on their overall results. If these studies are excluded from their meta-analyses of chemotherapy versus radiotherapy, the pooled results for survival with earlier stages of endometrial cancer would not be statistically significantly different. Following some controversy over the use of adjusted or unadjusted results in GOG 122, we considered it important to try to clarify the role of adjuvant chemotherapy for advanced endometrial cancer, by obtaining unpublished data from other similar trials. Our review of adjuvant chemotherapy in advanced disease, which incorporates unpublished data from Maggi 2006, suggests a survival advantage of adjuvant chemotherapy over radiotherapy in stage III/IV disease with minimal heterogeneity in meta-analyses using random-effects models. 
What remains to be determined is whether and in whom the addition of radiotherapy in advanced disease may be helpful. An ongoing trial commenced in 2009, of adjuvant chemoradiation and chemotherapy versus adjuvant chemotherapy alone in high risk endometrial cancer (defined in this trial as FIGO stage III/IV disease, and stage I/II clear cell and papillary serous), is expected to be completed in 2016 (GOG 0258). In this multicentre, parallel RCT, women are randomised to receive, either a 'sandwich' treatment of cisplatin (day 1 and 29), followed by radiotherapy and four cycles of carboplatin/paclitaxel, or six cycles of carboplatin/paclitaxel from day one. There have been no studies to date evaluating the 'sandwich' technique in advanced endometrial cancer, which may offer additional benefits.

A review of (non-adjuvant) chemotherapy for advanced, recurrent or metastatic endometrial carcinoma found evidence from eight RCTs that 'more chemotherapy' was associated with a longer overall survival than 'less chemotherapy' (Vale 2012). When it comes to adjuvant chemotherapy, this may not be the case. Mature data from GOG 184 are awaited with interest.

\section{AUTHORS' CONCLUSIONS}

\section{Implications for practice}

There is moderate quality evidence that chemotherapy increases survival time after primary surgery by approximately $25 \%$ relative to radiotherapy in stage III and IV endometrial cancer. There is limited evidence that it is associated with more adverse effects. There is some uncertainty as to whether triplet regimens offer similar survival benefits over doublet regimens in the long-term.
Further research is needed to determine which chemotherapy regimen/s are the most effective and least toxic, and whether the addition of radiotherapy further improves outcomes.

\section{Implications for research}

Further research is needed to determine whether the addition of radiotherapy improves survival in advanced endometrial cancer and to determine what is the optimal chemotherapy regimen/s with regard to survival, safety and QoL. Further research is needed to determine if these findings are consistent in older women.

A review of chemoradiation versus radiotherapy in advanced endometrial cancer, incorporating stage III data from the ongoing PORTEC-3 trial, will be valuable. For this, reviewers would need to obtain unpublished stage III data from the ILIADE trial (Hogberg 2010).

\section{ACK N O WLEDGEMENTS}

We thank Jo Morrison for clinical and editorial advice, Jane Hayes for designing the search strategy, and Gail Quinn and Clare Jess for their contributions to the editorial process. We are grateful to the Maggi 2006 trial investigators, particularly Irene Floriani and Roldano Fossati, for supplying unpublished data from this trial.

The National Institute for Health Research (NIHR) is the largest single funder of the Cochrane Gynaecological Cancer Group.

The views and opinions expressed therein are those of the authors and do not necessarily reflect those of the NIHR, NHS, or the Department of Health. 


\section{REFERE N CES}

\section{References to studies included in this review}

\section{GOG 122 \{published data only\}}

Bruner DW, Barsevick A, Tian C, Randall M, Mannel R, Cohn DE, et al. Randomized trial results of quality of life comparing whole abdominal irradiation and combination chemotherapy in advanced endometrial carcinoma: A Gynecologic Oncology Group study. Quality of Life Research 2007;16(1):89-100.

* Randall ME, Filiaci VL, Muss H, Spirtos NM, Mannel RS, Fowler J, et al. Randomized phase III trial of whole-abdominal irradiation versus doxorubicin and cisplatin chemotherapy in advanced endometrial carcinoma: a Gynecologic Oncology Group Study. Journal of Clinical Oncology 2006;24(1):36-44.

Tewari KS, Filiaci VL, Spirtos NM, Mannel RS, Thigpen JT, Cibull ML, et al. Association of number of positive nodes and cervical stroma invasion with outcome of advanced endometrial cancer treated with chemotherapy or whole abdominal irradiation: a Gynecologic Oncology Group study. Gynecologic Oncology 2012;125(1):87-93.

\section{GOG 184 \{published data only\}}

Homesley HD, Filiaci V, Gibbons SK, Long HJ, Cella D, Spirtos NM, et al. A randomized phase III trial in advanced endometrial carcinoma of surgery and volume directed radiation followed by cisplatin and doxorubicin with or without paclitaxel: A Gynecologic Oncology Group study. Gynecologic Oncology 2009;112(3):543-52.

\section{Maggi 2006 \{published data only\}}

Maggi R, Lissoni A, Spina F, Melpignano M, Zola P, Favalli G, et al. Adjuvant chemotherapy vs radiotherapy in high-risk endometrial carcinoma: results of a randomised trial. British Journal of Cancer 2006;95(3):266-71.

\section{Susumu 2008 \{published data only\}}

Susumu N, Sagae S, Udagawa Y, Niwa K, Kuramoto H, Satoh S, et al. Randomized phase III trial of pelvic radiotherapy versus cisplatin-based combined chemotherapy in patients with intermediate- and high-risk endometrial cancer: a Japanese Gynecologic Oncology Group study. Gynecologic Oncology 2008;108(1):226-33.

\section{References to studies excluded from this review}

\section{Aapro 2003 \{published data only\}}

Aapro MS, van Wijk FH, Bolis G, Chevallier B, van der Burg ME, Poveda $\mathrm{A}$, et al. Doxurubicin versus doxorubicin and cisplatin in endometrial carcinoma: definitive results of a randomised study (55872) by the EORTC Gynaecological Cancer Group. Annals of Oncology 2003;14(3):441-8.

\section{Fleming 2004a \{published data only\}}

* Fleming GF, Filiaci VL, Bentley RC, Herzog T, Sorosky J, Vaccarello L, et al. Phase III randomized trial of doxorubicin + cisplatin versus doxorubicin + 24-h paclitaxel + filgrastim in endometrial carcinoma: a Gynecologic Oncology Group study. Annals of Oncology 2004;15(8):1173-8.
Fleming 2004b \{published data only\}

* Fleming GF, Brunetto VL, Cella D, Look KY, Reid GC, Munkarah AR, et al. Phase III trial of doxorubicin plus cisplatin with or without paclitaxel plus filgrastim in advanced endometrial carcinoma: a Gynecologic Oncology Group Study. Journal of Clinical Oncology 2004;22(11):2159-66.

\section{Gallion 2003 \{published data only\}}

Gallion HH, Brunetto VL, Cibull M, Lentz SS, Reid G, Soper JT, et al. Randomized phase III trial of standard timed doxorubicin plus cisplatin versus circadian timed doxorubicin plus cisplatin in stage III and IV or recurrent endometrial carcinoma: a Gynecologic Oncology Group Study. Journal of Clinical Oncology 2003;21(20):3808-13.

\section{Hogberg 2010 \{published data only\}}

Hogberg T, Rosenberg P, Kristensen G, de Oliveira CF, de Pont Christensen $\mathrm{R}$, Sorbe $\mathrm{B}$, et al. A randomized phase III study on adjuvant treatment with radiation +/- chemotherapy in early-stage high-risk endometrial cancer (NSGO-EC-9501/ EORTC55991) [Abstract]. Journal of Clinical Oncology. Abstracts of the 43rd Annual Meeting of the American Society of Clinical Oncology 2007;25(18 Suppl):Abstract 5503.

* Hogberg T, Signorelli M, de Oliveira CF, Fossati R, Lissoni AA, Sorbe B, et al. Sequential adjuvant chemotherapy and radiotherapy in endometrial cancer--results from two randomised studies. European Journal of Cancer 2010;46(13):2422-31.

\section{Kuoppala 2008 \{published data only\}}

* Kuoppala T, Mäenpää J, Tomas E, Puistola U, Salmi T, Grenman S, et al. Surgically staged high-risk endometrial cancer: randomized study of adjuvant radiotherapy alone vs. sequential chemo-radiotherapy. Gynecologic Oncology 2008;110(2):190-5

\section{Mustea 2013 \{published data only\}}

Mustea A, Koensgen D, Belau A, Sehouli J, Lichtenegger W, Schneidewind L, et al. Adjuvant sequential chemoradiation therapy in high-risk endometrial cancer: results of a prospective, multicenter phase-II study of the NOGGO (NorthEastern German Society of Gynaecological Oncology). Cancer Chemotherapy and Pharmacology 2013;72(5):975-83.

Nomura 2011 \{published data only\}

Nomura H, Aoki D, Takahashi F, Katsumata N, Watanabe $\mathrm{Y}$, Konishi I, et al. Randomized phase II study comparing docetaxel plus cisplatin, docetaxel plus carboplatin, and paclitaxel plus carboplatin in patients with advanced or recurrent endometrial carcinoma: a Japanese Gynecologic Oncology Group study (JGOG2041). Annals of Oncology 2011;22(3):636-42.

\section{Wolfson 2007 \{published data only\}}

Wolfson AH, Brady MF, Rocereto T, Mannel RS, Lee Y-C, Futoran $\mathrm{RJ}$ et al. A gynecologic oncology group randomized phase III trial of whole abdominal irradiation (WAI) vs. cisplatinifosfamide and mesna (CIM) as post-surgical therapy in stage 
I-IV carcinosarcoma (CS) of the uterus. Gynecologic Oncology 2007;107(2):177-185.

\section{References to ongoing studies}

GOG 0258 \{published data only\}

Gynecologic Oncology Group. Carboplatin and paclitaxel with or without cisplatin and radiation therapy in treating patients with stage I, stage II, stage III, or stage IVA endometrial cancer. http://www.controlled-trials.com/mrct/trial/587551/ endometrial+cancer (accessed 11 November 2013).

\section{PORTEC-3 \{unpublished data only\}}

PORTEC-3 collaborators. Chemotherapy and radiation therapy compared with radiation therapy alone in treating patients with high-risk stage I, stage II, or stage III endometrial cancer. http:// www.controlled-trials.com/mrct/trial/386235/PORTEC-3 2012.

\section{Additional references}

\section{Barlin 2010}

Barlin JN, Puri I, Bristow RE. Cytoreductive surgery for advanced or recurrent endometrial cancer: a meta-analysis. Gynecologic Oncology 2010;118(1):14-8.

\section{Berek 2010}

Berek JS, Hacker NF. Berek and Hacker's Gynecologic Oncology. 5th edition. Lippincott Williams \& Wilkins, 2010.

\section{Colombo 2011}

Colombo N, Preti E, Landoni F, Carinelli S, Colombo A, Marini C, et al. Endometrial cancer: ESMO Clinical Practice Guidelines for diagnosis, treatment and follow-up. Annals of Oncology 2011;22(Suppl 6):vi35-39.

\section{Creasman 2006}

Creasman WT, Odicino F, Mausinneuve P, Quinn MA, Beller U, Benedet JL, et al. Carcinoma of the corpus uteri. FIGO 26th Annual Report on the Results of Treatment in Gynecological Cancer. International Journal of Gynaecology and Obstetrics 2006;95(Suppl 1):S105-43.

\section{CTCAE 2006}

Common terminology criteria for adverse events v3.0 (CTCAE). http://ctep.cancer.gov/forms/CTCAEv3.pdf 2006.

\section{Deeks 2001}

Deeks JJ, Altman DG, Bradburn MJ. Statistical methods for examining heterogeneity and combining results from several studies in meta-analysis. In: In: Egger M, Davey Smith G, Altman DG, editor(s). Systematic Reviews in Health Care: Meta-Analysis in Context. 2nd edition. London: BMJ Publication Group, 2001.

\section{Dubinsky 2004}

Dubinsky TJ. Value of sonography in the diagnosis of abnormal vaginal bleeding. Journal of Clinical Ultrasound 2004;32(7):34853.

\section{ENDNOTE X7.0.2 [Computer program]}

ENDNOTE X7.0.2. Thomson Reuters, 2013.

\section{Evans 2011}

Evans T, Sany O, Pearmain P, Ganesan R, Blann A, Sundar S. Differential trends in the rising incidence of endometrial cancer by type: data from a UK population-based registry from 1994 to 2006. British Journal of Cancer 2011;104(9):1505-10.

\section{Galaal 2013}

Galaal K, Al Moundhri M, Bryant A, Lopes AD. Surgery and chemotherapy with or without radiotherapy for disseminated advanced endometrial cancer. Cochrane Database of Systematic Reviews 2013, Issue 8. Art. No: CD010681. [DOI: 10.1002/14651858.CD010681]

\section{Higgins 2003}

Higgins JPT, Thompson SG, Deeks JJ, Altman DG. Measuring inconsistency in meta-analyses. BMJ 2003;327(7414):557-60.

\section{Higgins 2011}

Higgins JPT, Green S (editors). Cochrane Handbook for Systematic Reviews of Interventions. Version 5.1. The Cochrane Collaboration, 2011. Available from www.cochranehandbook.org.

\section{Humber 2007}

Humber CE, Tierney JF, Symonds RP, Collingwood M, Kirwan J, Williams $\mathrm{C}$, et al. Chemotherapy for advanced, recurrent or metastatic endometrial cancer: a systematic review of Cochrane Collaboration. Annals of Oncology 2007;18(3):409-20.

\section{IARC 2013}

The International Agency for Research on Cancer. GLOBOCAN 2012: Estimated cancer incidence, mortality and prevalence worldwide in 2012. http://globocan.iarc.fr/Pages/ fact_sheets_population.aspx 2013.

\section{Jemal 2008}

Jemal A, Siegel R, Ward E, Hao Y, Xu J, Murray T, et al. Cancer statistics, 2008. CA: A Cancer Journal for Clinicians 2008;58(2):71-96.

\section{Jemal 2011}

Jemal A, Bray F, Center MM , Ferlay J, Ward E, Forman D. Global cancer statistics. CA: A Cancer Journal for Clinicians 2011;61(2):69-90.

\section{Johnson 2011}

Johnson N, Bryant A, Miles T, Hogberg T, Cornes P. Adjuvant chemotherapy for endometrial cancer after hysterectomy. Cochrane Database of Systematic Reviews 2011, Issue 10. Art. No: CD003175. [DOI: 10.1002/14651858.CD003175.pub2]

\section{Kokka 2010}

Kokka F, Brockbank E, Oram D, Gallagher C, Bryant A. Hormonal therapy in advanced or recurrent endometrial cancer. Cochrane Database of Systematic Reviews 2010, Issue 12. Art. No: CD007926. [DOI: 10.1002/14651858.CD007926.pub2]

\section{Martin-Hirsch 2011}

Martin-Hirsch PPL, Bryant A, Keep SL, Kitchener HC, Lilford R. Adjuvant progestagens for endometrial cancer. Cochrane 
Database of Systematic Reviews 2011, Issue 6. Art. No: CD001040. [DOI: 10.1002/14651858.CD001040.pub2]

\section{McMeekin 2009}

McMeekin DS. Where is the future of endometrial cancer therapy? Annals of Oncology 2009;20(11):1757-61.

\section{Review Manager (RevMan) [Computer program]}

The Nordic Cochrane Centre, The Cochrane Collaboration Review Manager (RevMan). Version 5.2. Copenhagen: The Nordic Cochrane Centre, The Cochrane Collaboration, 2012.

\section{SEER 2007}

Kosary CL. Chapter 15: Cancer of the corpus uteri. In: Gloeckler Ries LA, Young JL, Keel GE, Eisner MP, Lin YD, Horner M-J,

\section{CHARACTERISTICS OF STUDIES}

Characteristics of included studies [ordered by study ID] editors(s). Cancer survival among adults: US SEER program, 1988-2001. Patient and Tumor Characteristics. Bethesda, MD National Cancer Institute, 2007:123-132.

\section{Vale 2012}

Vale CL, Tierney J, Bull SJ, Symonds PR. Chemotherapy for advanced, recurrent or metastatic endometrial carcinoma. Cochrane Database of Systematic Reviews 2012, Issue 8. Art. No: CD003915. [DOI: 10.1002/14651858.CD003915.pub4]

* Indicates the major publication for the study

\section{GOG 122}

\section{Study characteristics}

Methods $\quad$ Multicentre parallel RCT conducted in the USA. Recruitment between 1992 and 2000.

\section{Participants}

422 women were enrolled (396 assessable).

Women with FIGO stage III or IV endometrial cancer of any histology. CRS included hysterectomy and BSO, surgical staging, and tumour resection to a maximum of $2 \mathrm{~cm}$ residual tumour at a single site. Nodal sampling was optional for women with stage III or IV by clinical or surgical criteria.

Women were ineligible if they had recurrent disease; liver, lung or haematogenous metastases; or a history of chemotherapy or radiotherapy.

Protocol treatment was to be started within eight weeks of CRS.

Interventions

Arm 1 (194 women): doxorubicin $\left(60 \mathrm{mg} / \mathrm{m}^{2}\right)$ and cisplatin $\left(50 \mathrm{mg} / \mathrm{m}^{2}\right)$ every three weeks for seven cycles, followed by one cycle of cisplatin (AP)

Arm 2 (202 women): whole body irradiation (WAI); 30 Gy in 20 fractions with a 15 Gy boost

Outcomes PFS (5-year), OS, toxicity, QoL

Notes

Baseline characteristics overall, were: $50 \%$ endometrioid tumours; $27 \%$ stage IV; $52 \%$ grade $3 ; 86 \%$ absent or microscopic residual disease; $95 \%$ performance status $0-1$; median age 63 years. Risk factors for poorer prognosis were slightly skewed in favour of the WAI arm.

Median follow-up was 74 months. WAI group was evaluated weekly during WAl; AP group was evaluated before each AP cycle (every three weeks). After protocol treatment, women were evaluated every three months for two years, then every six months.

\section{Risk of bias}

\begin{tabular}{lll}
\hline Bias & Authors' judgement & Support for judgement \\
\hline $\begin{array}{l}\text { Random sequence genera- } \\
\text { tion (selection bias) }\end{array}$ & Low risk & $\begin{array}{l}\text { Balanced block randomisation in ratio 1:1; balanced assignment within each } \\
\text { institution. }\end{array}$ \\
\hline $\begin{array}{l}\text { Allocation concealment } \\
\text { (selection bias) }\end{array}$ & Low risk & $\begin{array}{l}\text { Allocation was concealed until telephone registration with verification of eligi- } \\
\text { bility. }\end{array}$ \\
\hline \hline
\end{tabular}


GOG 122 (Continued)

Blinding of participants Unclear risk An unblinded trial; however, performance bias is unlikely to have an impact on and personnel (perforsurvival data.

mance bias)

All outcomes

\begin{tabular}{|c|c|c|}
\hline $\begin{array}{l}\text { Blinding of outcome as- } \\
\text { sessment (detection bias) } \\
\text { All outcomes }\end{array}$ & Low risk & $\begin{array}{l}\text { Pathology materials of primary and progressive disease were reviewed by the } \\
\text { GOG Pathology Committee. A central review of eligibility data was conducted } \\
\text { by the GOG Gynecologic Oncology Committee without knowledge of outcome }\end{array}$ \\
\hline
\end{tabular}

Incomplete outcome data Low risk

(attrition bias)

Missing data was $<10 \%$.

All outcomes

\begin{tabular}{|c|c|c|}
\hline $\begin{array}{l}\text { Selective reporting (re- } \\
\text { porting bias) }\end{array}$ & Unclear risk & $\begin{array}{l}\text { All expected outcomes were reported. Adjusted results were reported which } \\
\text { increased the magnitude of the effect in favour of chemotherapy. }\end{array}$ \\
\hline
\end{tabular}

Other bias Low risk A well-designed and conducted trial. ITT analyses.

GOG 184

\section{Study characteristics}

\begin{tabular}{ll}
\hline Methods & Multicentre parallel RCT conducted in the USA. Recruitment from 2000 to 2004. \\
\hline Participants & 659 women were enrolled. \\
& Women with FIGO stage III/IV endometrial cancer of any histology, with disease limited to the pelvis \\
and abdomen were eligible. Women were not eligible if they had recurrent disease, previous radiother- \\
apy, previous malignancy within five years, serious comorbidity, and survival expected to be < three \\
months. \\
All women received CRS and volume-directed radiation to pelvic lymph nodes, with or without para- \\
aortic lymph nodes. CRS included hysterectomy and BSO. Radiotherapy was initiated within eight \\
weeks of CRS. \\
After the results of GOG 122 were known, women with stage IV were no longer eligible as GOG 122 \\
showed a significant benefit with adjuvant chemotherapy after surgery in this group, compared with \\
adjuvant radiotherapy.
\end{tabular}

Interventions Chemotherapy was initiated within eight weeks of radiotherapy.

Arm 1 (282 women) = Day 1:cisplatin $\left(50 \mathrm{mg} / \mathrm{m}^{2}\right) /$ doxorubicin $\left(45 \mathrm{mg} / \mathrm{m}^{2}\right) /$ Day 2:paclitaxel $(160 \mathrm{mg} /$ $\mathrm{m}^{2}$ ), every 21 days for six cycles. G-CSF given to all women.

Arm $2(270$ women $)=$ Day 1:cisplatin $\left(50 \mathrm{mg} / \mathrm{m}^{2}\right) /$ doxorubicin $\left(45 \mathrm{mg} / \mathrm{m}^{2}\right)$ every 21 days for six cycles. G-CSF initially optional, then in 2002 it was included in the control regimen for all women.

Outcomes RFS (3 year), OS, loco-regional recurrence, distant recurrence, adverse events

Notes

OS data were not mature at the time of the 2009 report. We were unsuccessful in obtaining these mature data from the investigators.

Baseline characteristics overall, were: $69 \%$ endometrioid tumours; $12 \%$ stage IV; $41 \%$ grade $3 ; 90 \%$ absent or microscopic residual disease; $99 \%$ performance status $0-1$; median age 58 years. Median follow-up was 47 and 46 months for the trial arms, respectively.

\section{Risk of bias}

Adjuvant chemotherapy for advanced endometrial cancer (Review) 
GOG 184 (Continued)

\begin{tabular}{|c|c|c|}
\hline Bias & Authors' judgement & Support for judgement \\
\hline $\begin{array}{l}\text { Random sequence genera- } \\
\text { tion (selection bias) }\end{array}$ & Low risk & $\begin{array}{l}\text { Central random assignment by the GOG Statistical and Data Center after CRS } \\
\text { and radiotherapy. Randomisation was in balanced blocks. }\end{array}$ \\
\hline $\begin{array}{l}\text { Allocation concealment } \\
\text { (selection bias) }\end{array}$ & Low risk & $\begin{array}{l}\text { Randomisation was concealed from institutions and patients until centrally al- } \\
\text { located. }\end{array}$ \\
\hline $\begin{array}{l}\text { Blinding of participants } \\
\text { and personnel (perfor- } \\
\text { mance bias) } \\
\text { All outcomes }\end{array}$ & Unclear risk & $\begin{array}{l}\text { An unblinded trial; however, performance bias is unlikely to have an impact on } \\
\text { survival data. }\end{array}$ \\
\hline $\begin{array}{l}\text { Blinding of outcome as- } \\
\text { sessment (detection bias) } \\
\text { All outcomes }\end{array}$ & Low risk & $\begin{array}{l}\text { Central review of data and pathology materials was performed and a central } \\
\text { review of eligibility data was conducted by the GOG Gynecologic Oncology } \\
\text { Committee without knowledge of outcome. }\end{array}$ \\
\hline $\begin{array}{l}\text { Incomplete outcome data } \\
\text { (attrition bias) } \\
\text { All outcomes }\end{array}$ & Low risk & Missing data was $<10 \%$. \\
\hline $\begin{array}{l}\text { Selective reporting (re- } \\
\text { porting bias) }\end{array}$ & Low risk & All expected outcomes were reported. \\
\hline Other bias & Low risk & A well-designed and conducted trial. ITT analyses. \\
\hline
\end{tabular}

Maggi 2006

\section{Study characteristics}

\begin{tabular}{ll}
\hline Methods & Multicentre parallel RCT conducted in Italy. Recruitment from 1990 to 1997. \\
\hline Participants & 345 women were randomised after surgical staging. 340 were analysed. \\
& Inclusion criteria were high-risk endometrial cancer defined as stage IcG3 and stage IIG3 with > 50\% \\
myometrial invasion, or stage III. & \\
All women underwent CRS as primary treatment (TAH-BSO, with or without partial colpectomy and \\
pelvic and lumbo-aortic lymph node sampling). Protocol treatment was started within 30 days of \\
surgery.
\end{tabular}

$\begin{array}{ll}\text { Interventions } & \begin{array}{l}\text { Arm 1: doxorubicin }\left(45 \mathrm{mg} / \mathrm{m}^{2}\right) \text {, cisplatin }\left(50 \mathrm{mg} / \mathrm{m}^{2}\right) \text { and cyclophosphamide }\left(600 \mathrm{mg} / \mathrm{m}^{2}\right) \text { every four } \\ \text { weeks for five cycles. }\end{array}\end{array}$

Arm 2: external beam radiation therapy (45-50 Gy on a five days per week schedule).

\begin{tabular}{ll}
\hline Outcomes & 3,5 and 7 -year OS and PFS; toxicity. \\
\hline Notes & $\begin{array}{l}\text { Randomisation was stratified by stage of disease with approximately } 26.5 \% \text { stage I, 9\% stage II and } 64 \% \\
\text { stage III disease. }\end{array}$ \\
& $\begin{array}{l}\text { Baseline characteristics of the groups were similar overall, including stage: } 57 \% \text { grade } 3,72 \% \text { had my- } \\
\text { ometrial invasion }>50 \%, \text { median age } 62.5 \text { years; residual disease not reported. }\end{array}$
\end{tabular}


Maggi 2006 (Continued)

Median follow-up was 95.5 months. For the purposes of this review, we included only the stage III survival data which we obtained from the trial investigators via email on the $23 / 12 / 2013$. We did not obtain separate stage III baseline data.

\section{Risk of bias}

\begin{tabular}{|c|c|c|}
\hline Bias & Authors' judgement & Support for judgement \\
\hline $\begin{array}{l}\text { Random sequence genera- } \\
\text { tion (selection bias) }\end{array}$ & Low risk & $\begin{array}{l}\text { "Randomisation was carried out centrally by telephone and patients were } \\
\text { stratified by institution and stage of disease". }\end{array}$ \\
\hline $\begin{array}{l}\text { Allocation concealment } \\
\text { (selection bias) }\end{array}$ & Low risk & $\begin{array}{l}\text { Randomisation was concealed from institutions and patients until centrally al- } \\
\text { located. }\end{array}$ \\
\hline $\begin{array}{l}\text { Blinding of participants } \\
\text { and personnel (perfor- } \\
\text { mance bias) } \\
\text { All outcomes }\end{array}$ & Unclear risk & $\begin{array}{l}\text { An unblinded trial (blinding not possible due to the nature of the interven- } \\
\text { tions). }\end{array}$ \\
\hline $\begin{array}{l}\text { Blinding of outcome as- } \\
\text { sessment (detection bias) } \\
\text { All outcomes }\end{array}$ & Unclear risk & $\begin{array}{l}\text { Unblinded. Progression was assessed or detected by pelvic examination, } \\
\text { pathological examination of vault smears, and annual chest radiographs. If } \\
\text { progression was suspected, other diagnostic tests were performed. }\end{array}$ \\
\hline $\begin{array}{l}\text { Incomplete outcome data } \\
\text { (attrition bias) } \\
\text { All outcomes }\end{array}$ & Low risk & Missing data was $<10 \%$. \\
\hline $\begin{array}{l}\text { Selective reporting (re- } \\
\text { porting bias) }\end{array}$ & Low risk & All expected outcomes were reported. \\
\hline Other bias & Low risk & A well-designed and conducted trial. ITT analyses. \\
\hline
\end{tabular}

\section{Susumu 2008}

\section{Study characteristics}

\begin{tabular}{|c|c|}
\hline Methods & Multicentre RCT conducted in Japan. Recruitment from 1994 to 2000. \\
\hline \multirow[t]{2}{*}{ Participants } & $\begin{array}{l}475 \text { women were randomised but only } 385 \text { were analysed as } 41 \text { were found to be ineligible and } 49 \text { had } \\
\text { non-endometrioid histology. }\end{array}$ \\
\hline & $\begin{array}{l}\text { Inclusion criteria were age }<75 \text { years, WHO performance status of } 0-3 \text {, FIGO stage IC - IIIC with myome- } \\
\text { trial invasion }>50 \% \text {. All women underwent CRS as primary treatment (TAH/BSO and, ideally, pelvic and } \\
\text { paraaortic lymphadenectomy) and had no residual tumour. Patients were excluded if previously treat- } \\
\text { ed with surgery, chemotherapy or radiotherapy for another cancer. }\end{array}$ \\
\hline
\end{tabular}

Interventions

All women received CRS. Treatment was initiated within four weeks of surgery.

Arm 1: adjuvant doxorubicin $\left(40 \mathrm{mg} / \mathrm{m}^{2}\right)$, cisplatin $\left(50 \mathrm{mg} / \mathrm{m}^{2}\right)$ and cyclophosphamide $\left(333 \mathrm{mg} / \mathrm{m}^{2}\right)$ every four weeks for three or more cycles.

Arm 2: adjuvant external beam radiation therapy (45-50 Gy on a five days per week schedule).

\begin{tabular}{ll}
\hline Outcomes & Five year OS, PFS and toxicity \\
\hline Notes & $\begin{array}{l}\text { Randomisation was not stratified by stage, however treatment groups had similar numbers of women } \\
\text { with stage III disease ( } 47 \text { and } 50 \text { women in the radiotherapy and chemotherapy groups, respectively). }\end{array}$ \\
\hline
\end{tabular}


Baseline characteristics of the groups were similar overall, including stage: 53\% grade 3, 100\% had myometrial invasion $>50 \%, 37 \%$ lymphovascular space invasion, $0 \%$ non-endometrioid histology, mean age 59 years. We did not obtain separate baseline data for stage III women.

Median follow-up was 60 months.

Only 97 women (25\%) had stage III endometrial cancer. The investigators define a high risk group of 75 women with IIIB/C, or stage IIIA with other risk factors. From the trial publication, it is not clear how many of these women were allocated to each trial group. However, we have used the survival data in our analyses in the meantime and have requested complete stage III data from the trial investigators.

\section{Risk of bias}

\begin{tabular}{|c|c|c|}
\hline Bias & Authors' judgement & Support for judgement \\
\hline $\begin{array}{l}\text { Random sequence genera- } \\
\text { tion (selection bias) }\end{array}$ & Low risk & $\begin{array}{l}\text { Simple randomisation was performed. "Each participant was assigned by a } \\
\text { central telephone system". }\end{array}$ \\
\hline $\begin{array}{l}\text { Allocation concealment } \\
\text { (selection bias) }\end{array}$ & Low risk & Assigned by a central telephone system. \\
\hline $\begin{array}{l}\text { Blinding of participants } \\
\text { and personnel (perfor- } \\
\text { mance bias) } \\
\text { All outcomes }\end{array}$ & Unclear risk & $\begin{array}{l}\text { An unblinded trial (blinding not possible due to the nature of the interven- } \\
\text { tions). }\end{array}$ \\
\hline $\begin{array}{l}\text { Blinding of outcome as- } \\
\text { sessment (detection bias) } \\
\text { All outcomes }\end{array}$ & Unclear risk & $\begin{array}{l}\text { Method of detection of progression not described; however, the primary out- } \\
\text { come (OS) is unlikely to be affected. }\end{array}$ \\
\hline $\begin{array}{l}\text { Incomplete outcome data } \\
\text { (attrition bias) } \\
\text { All outcomes }\end{array}$ & Unclear risk & $\begin{array}{l}49 \text { participants ( } 10 \%) \text { were excluded after randomisation due to non-en- } \\
\text { dometrioid histology ( } 27 \text { and } 22 \text { in RT and CT groups respectively) and } 41 \text { were } \\
\text { deemed ineligible ( } 18 \text { and } 23 \text { respectively). This might be explained if randomi- } \\
\text { sation was performed before surgical staging. }\end{array}$ \\
\hline $\begin{array}{l}\text { Selective reporting (re- } \\
\text { porting bias) }\end{array}$ & Low risk & $\begin{array}{l}\text { All expected outcomes were reported. We obtained unpublished subgroup da- } \\
\text { ta from the investigators on the } 21 / 3 / 2014 \text {. }\end{array}$ \\
\hline Other bias & Low risk & None noted. ITT analyses. \\
\hline
\end{tabular}

$\mathrm{RCT}$ = randomised controlled trial; $\mathrm{CRS}$ = cytoreductive surgery; $\mathrm{BSO}=$ bilateral salpingo-oophrectomy; FIGO = International Federation of Gynecology and Obstetrics; PFS = progression-free survival; RFS = recurrence free survival; OS = overall survival; ITT = intention to treat.

Characteristics of excluded studies [ordered by study ID]

\begin{tabular}{ll}
\hline Study & Reason for exclusion \\
\hline Aapro 2003 & $\begin{array}{l}\text { RCT of chemotherapy only (CD versus doxorubicin only) in women with advanced or recurrent dis- } \\
\text { ease. CRS was not performed. This study is included in the Cochrane review of chemotherapy for } \\
\text { (non-adjuvant) recurrent and metastatic endometrial cancer (Vale 2012). }\end{array}$ \\
\hline Fleming 2004a & $\begin{array}{l}\text { RCT of CD versus DP in women with advanced or recurrent endometrial cancer. Included patients } \\
\text { with recurrent disease which was not amenable to surgery. This study is included in the Cochrane } \\
\text { review of (non-adjuvant) chemotherapy for advanced, recurrent and metastatic endometrial can- } \\
\text { cer (Vale 2012). }\end{array}$ \\
\hline
\end{tabular}




\begin{tabular}{ll}
\hline Study & Reason for exclusion \\
\hline Fleming 2004b & $\begin{array}{l}\text { RCT of CD versus CDP in women with advanced or recurrent endometrial cancer. Included patients } \\
\text { with recurrent disease which was not amenable to surgery. This study is included in the Cochrane } \\
\text { review of (non-adjuvant) chemotherapy for advanced, recurrent and metastatic endometrial can- } \\
\text { cer (Vale 2012). }\end{array}$
\end{tabular}

$\begin{array}{ll}\text { Gallion } 2003 & \text { RCT of standard timing versus circadian timing of chemotherapy (CD) in women with advanced } \\ \text { or recurrent disease. CRS was not performed. This study is included in the Cochrane review of } \\ \text { chemotherapy for (non-adjuvant) recurrent and metastatic endometrial cancer (Vale 2012). }\end{array}$

Hogberg 2010

RCT of high-risk endometrial cancer (HREC) participants (including 20\% stage III participants) evaluating radiotherapy versus chemoradiation. This study is included in the Cochrane review of adjuvant chemotherapy for (any stage) endometrial cancer (Johnson 2011).

Kuoppala 2008

RCT of 156 HREC participants (including 20 stage IIIA participants [12\%]) evaluating adjuvant radiotherapy versus sequential chemoradiation. This study is included in the Cochrane review of adjuvant chemotherapy for (any stage) endometrial cancer (Johnson 2011).

Mustea 2013 Feasibility study of chemoradiation in advanced disease, not a RCT.

Nomura 2011

RCT of cisplatin/docetaxel versus carboplatin/docetaxel versus carboplatin/paclitaxel in women with advanced or recurrent endometrial cancer with measurable disease (non-adjuvant chemotherapy).

Wolfson 2007

This RCT was conducted in women with uterine sarcomas not endometrial carcinoma.

$C D=$ cisplatin/doxorubicin; $C D P=$ cisplatin/doxorubicin/paclitaxel; $D P=$ doxorubicin/paclitaxel; $C R S$ = cytoreductive surgery.

Characteristics of ongoing studies [ordered by study ID]

\section{GOG 0258}

\begin{tabular}{ll}
\hline Study name & $\begin{array}{l}\text { Carboplatin and paclitaxel with or without cisplatin and radiation therapy in treating patients with } \\
\text { endometrial cancer }\end{array}$ \\
\hline Methods & Phase III multi-centre open label RCT \\
\hline Participants & $\begin{array}{l}\text { Women with high risk endometrial cancer (surgical stage III/IV advanced and stage I/II clear cell or } \\
\text { serous papillary) }\end{array}$ \\
\hline Interventions & $\begin{array}{l}\text { Arm 1: cisplatin on days } 1 \text { and 29 + EBRT for six weeks. Thereafter, four courses of carbo/paclitaxel. } \\
\text { ('sandwich' technique) }\end{array}$ \\
\hline Arm 2: carbo/paclitaxel x six courses starting on day 1. \\
\hline Starting date & RFS, OS, early and late adverse effects, QoL \\
\hline Contact information & June 2009 \\
\hline Notes & Daniela Matei \\
\hline
\end{tabular}


PORTEC-3

\begin{tabular}{ll}
\hline Study name & $\begin{array}{l}\text { Randomized phase III trial comparing concurrent chemoradiation and adjuvant chemotherapy } \\
\text { with pelvic radiation alone in high risk and advanced stage endometrial carcinoma: PORTEC-3 }\end{array}$ \\
\hline Methods & Phase III multicentre, open label RCT stratified according to participating group. \\
\hline Participants & $\begin{array}{l}\text { Women with endometrial cancer stage IB/C and IIA grade 3, stage IIB any grade, stage IIIA (grade } 3 \\
\text { or more than just peritoneal cytology) or IIIC, or serous or clear cell histology stage IB-III. No resid- } \\
\text { ual tumour or uterine sarcoma. Lymphadenectomy, or full surgical staging, or both allowed. }\end{array}$ \\
\hline Interventions & $\begin{array}{l}\text { Arm 1: cisplatin on days } 1 \text { and 22 + EBRT for six weeks (with vaginal brachytherapy for cervical in- } \\
\text { volvement). Thereafter, up to four courses of carbo/paclitaxel ('sandwich' technique) }\end{array}$ \\
\hline Arm 2: EBRT for six weeks (with vaginal brachytherapy for cervical involvement)
\end{tabular}

$\mathrm{RT}$ = radiotherapy; $\mathrm{CT}$ = chemotherapy; $\mathrm{QoL}$ = quality of life; RFS = recurrence-free survival; $\mathrm{OS}$ = overall survival.

\section{DATA AND ANALYSES}

\section{Comparison 1. Chemotherapy vs radiotherapy}

\begin{tabular}{|c|c|c|c|c|}
\hline $\begin{array}{l}\text { Outcome or subgroup ti- } \\
\text { tle }\end{array}$ & No. of studies & $\begin{array}{l}\text { No. of partici- } \\
\text { pants }\end{array}$ & Statistical method & Effect size \\
\hline 1.1 OS (Stage III/IV) & 2 & & Hazard Ratio (IV, Random, 95\% CI) & Subtotals only \\
\hline 1.1.1 Stage III & 2 & 514 & Hazard Ratio (IV, Random, 95\% CI) & $0.76[0.57,1.02]$ \\
\hline 1.1.2 Stage IV & 1 & 106 & Hazard Ratio (IV, Random, 95\% CI) & $0.68[0.44,1.04]$ \\
\hline 1.1.3 Stage III/IV & 2 & 620 & Hazard Ratio (IV, Random, 95\% CI) & $0.75[0.57,0.99]$ \\
\hline $\begin{array}{l}1.2 \text { OS (stage III/IV) (unad- } \\
\text { justed data) }\end{array}$ & 2 & & Hazard Ratio (IV, Random, 95\% CI) & $0.75[0.60,0.94]$ \\
\hline $\begin{array}{l}1.3 \text { OS (stage III/IV dichoto- } \\
\text { mous) }\end{array}$ & 2 & 620 & Risk Ratio $(\mathrm{M}-\mathrm{H}$, Random, 95\% Cl) & $0.79[0.68,0.93]$ \\
\hline 1.4 OS (Stage III only) & 2 & & Hazard Ratio (IV, Random, 95\% CI) & Subtotals only \\
\hline 1.4.1 Stage IIIA & 2 & 234 & Hazard Ratio (IV, Random, 95\% CI) & $0.61[0.38,0.98]$ \\
\hline 1.4.2 Stage IIIC & 2 & 265 & Hazard Ratio (IV, Random, 95\% CI) & $0.76[0.53,1.09]$ \\
\hline $\begin{array}{l}1.5 \text { OS (Stage III dichoto- } \\
\text { mous) }\end{array}$ & 2 & 514 & Risk Ratio (M-H, Random, 95\% Cl) & $0.76[0.62,0.93]$ \\
\hline
\end{tabular}




\begin{tabular}{|c|c|c|c|c|}
\hline $\begin{array}{l}\text { Outcome or subgroup ti- } \\
\text { tle }\end{array}$ & No. of studies & $\begin{array}{l}\text { No. of partici- } \\
\text { pants }\end{array}$ & Statistical method & Effect size \\
\hline 1.6 PFS (Stage III/IV) & 2 & & Hazard Ratio (IV, Random, 95\% CI) & Subtotals only \\
\hline 1.6.1 Stage III & 2 & 514 & Hazard Ratio (IV, Random, 95\% CI) & $0.81[0.63,1.05]$ \\
\hline 1.6.2 Stage IV & 1 & 106 & Hazard Ratio (IV, Random, 95\% CI) & $0.57[0.38,0.86]$ \\
\hline 1.6.3 Stage III/IV & 2 & 620 & Hazard Ratio (IV, Random, 95\% CI) & $0.74[0.59,0.92]$ \\
\hline $\begin{array}{l}1.7 \text { PFS (stage III/IV di- } \\
\text { chotomous) }\end{array}$ & 2 & 620 & Risk Ratio (M-H, Random, 95\% Cl) & $0.89[0.77,1.02]$ \\
\hline 1.8 PFS (Stage III only) & 2 & & Hazard Ratio (IV, Random, 95\% CI) & Subtotals only \\
\hline 1.8.1 Stage IIIA & 2 & 234 & Hazard Ratio (IV, Random, 95\% CI) & $0.66[0.43,1.01]$ \\
\hline 1.8.2 Stage IIIC & 2 & 265 & Hazard Ratio (IV, Random, 95\% CI) & $0.86[0.61,1.21]$ \\
\hline $\begin{array}{l}\text { 1.9 PFS (Stage III dichoto- } \\
\text { mous) }\end{array}$ & 2 & 514 & Risk Ratio (M-H, Random, 95\% Cl) & $0.84[0.70,1.01]$ \\
\hline $\begin{array}{l}\text { 1.10 Severe adverse } \\
\text { events }(G 3 / 4)\end{array}$ & 1 & & Risk Ratio (M-H, Random, 95\% Cl) & Totals not selected \\
\hline 1.10.1 Leukopenia & 1 & & Risk Ratio (M-H, Random, 95\% Cl) & Totals not selected \\
\hline 1.10.2 Neutropenia & 1 & & Risk Ratio (M-H, Random, 95\% Cl) & Totals not selected \\
\hline 1.10.3 Thrombocytopenia & 1 & & Risk Ratio (M-H, Random, 95\% Cl) & Totals not selected \\
\hline 1.10.4 Gastrointestinal & 1 & & Risk Ratio (M-H, Random, 95\% Cl) & Totals not selected \\
\hline 1.10.5 Neurological & 1 & & Risk Ratio (M-H, Random, 95\% Cl) & Totals not selected \\
\hline 1.10.6 Infection & 1 & & Risk Ratio (M-H, Random, 95\% Cl) & Totals not selected \\
\hline 1.10.7 Skin & 1 & & Risk Ratio (M-H, Random, 95\% Cl) & Totals not selected \\
\hline 1.10.8 Genitourinary & 1 & & Risk Ratio (M-H, Random, 95\% Cl) & Totals not selected \\
\hline 1.10.9 Alopecia & 1 & & Risk Ratio (M-H, Random, 95\% Cl) & Totals not selected \\
\hline $\begin{array}{l}1.11 \text { Treatment discontin- } \\
\text { uation due to toxicity }\end{array}$ & 1 & & Risk Ratio $(\mathrm{M}-\mathrm{H}$, Random, 95\% Cl) & Subtotals only \\
\hline $\begin{array}{l}1.12 \text { Treatment-related } \\
\text { deaths }\end{array}$ & 2 & 620 & Risk Ratio (M-H, Random, 95\% Cl) & $1.67[0.55,5.00]$ \\
\hline
\end{tabular}


Analysis 1.1. Comparison 1: Chemotherapy vs radiotherapy, Outcome 1: OS (Stage III/IV)

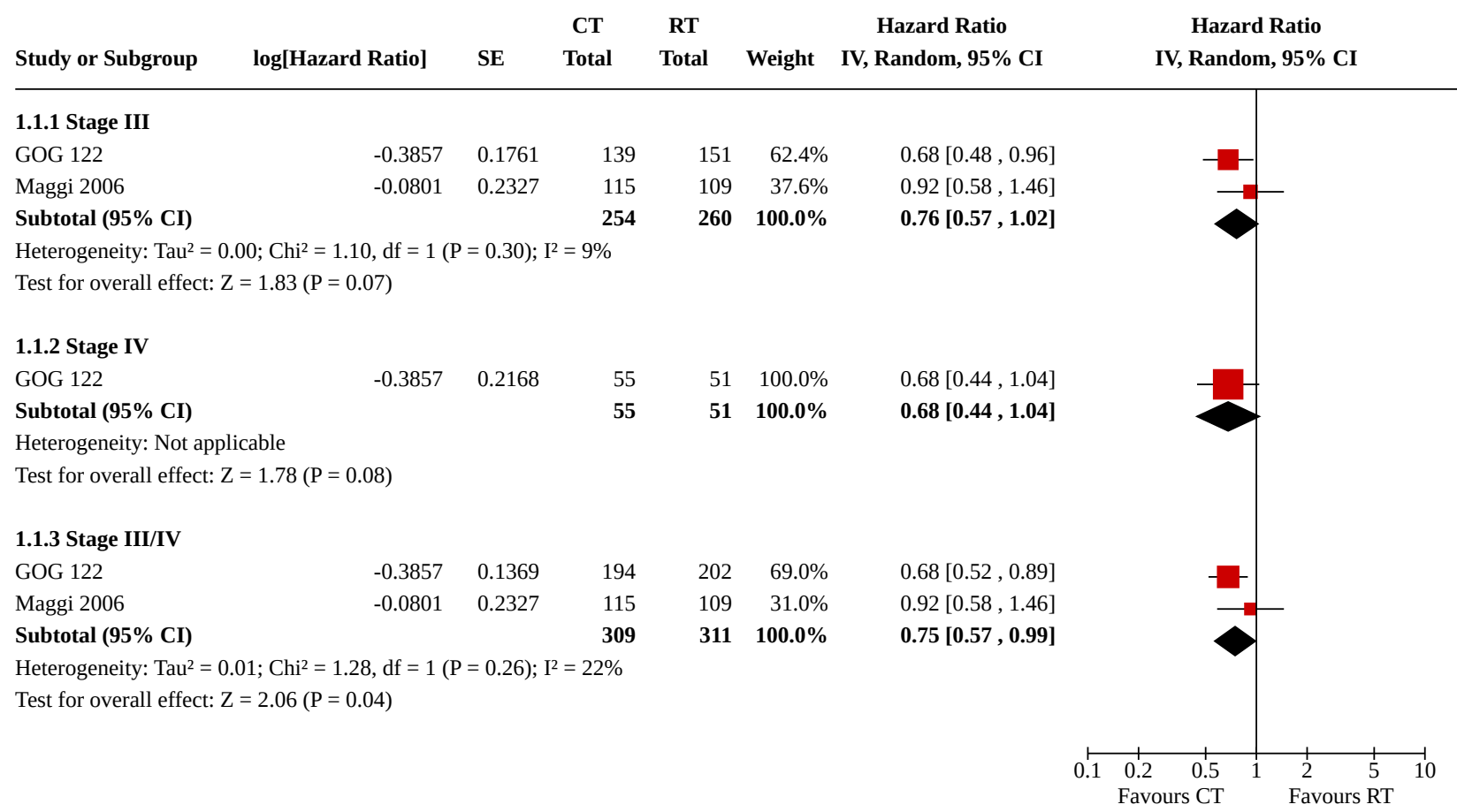

Analysis 1.2. Comparison 1: Chemotherapy vs radiotherapy, Outcome 2: OS (stage III/IV) (unadjusted data)

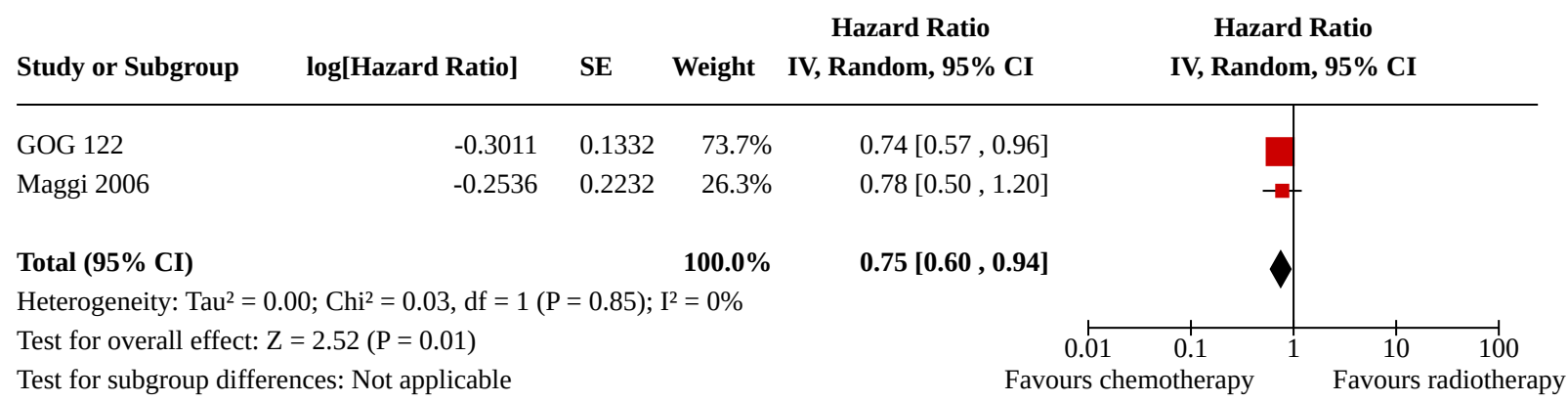

\section{Analysis 1.3. Comparison 1: Chemotherapy vs radiotherapy, Outcome 3: OS (stage III/IV dichotomous)}

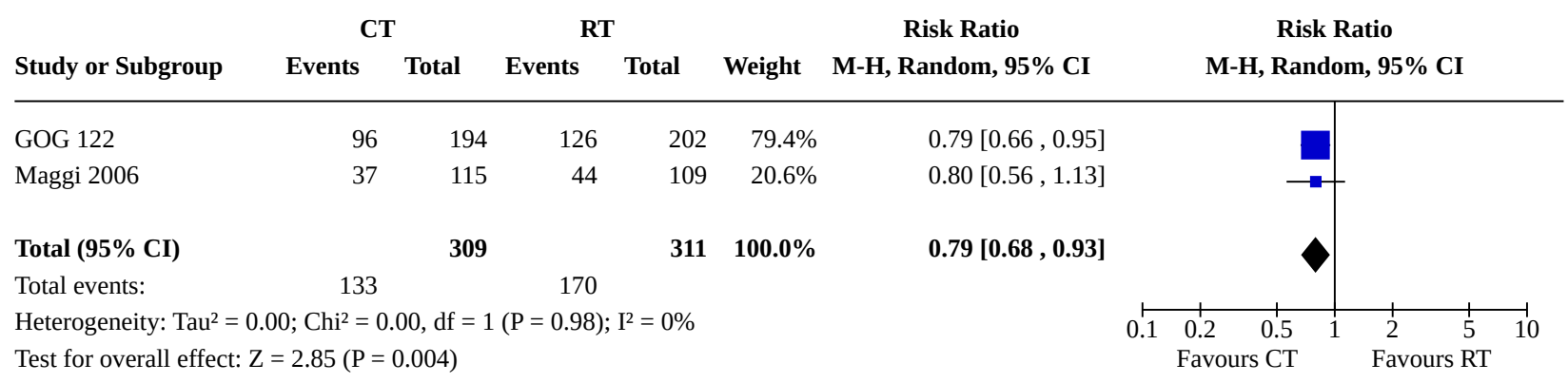


Analysis 1.4. Comparison 1: Chemotherapy vs radiotherapy, Outcome 4: OS (Stage III only)

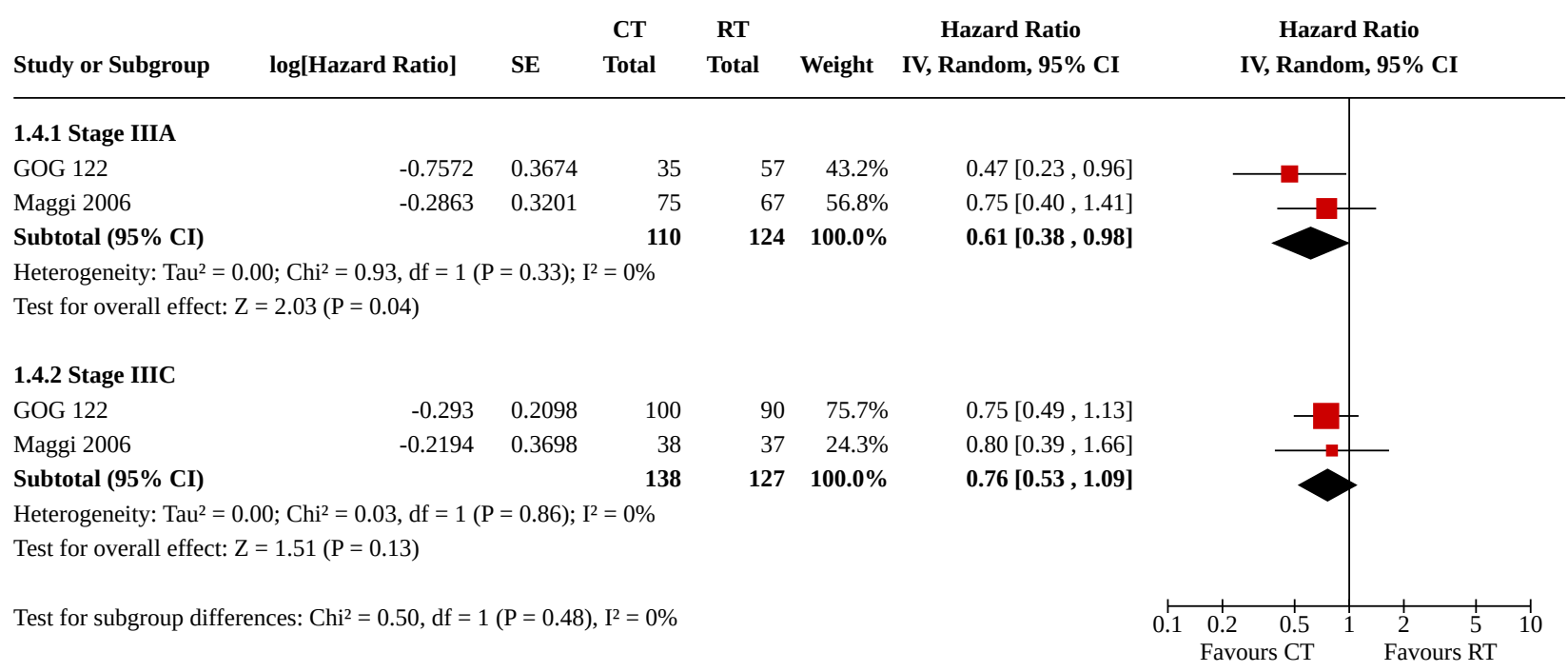

Analysis 1.5. Comparison 1: Chemotherapy vs radiotherapy, Outcome 5: OS (Stage III dichotomous)
CT
Risk Ratio
Risk Ratio

Total Events

Study or Subgroup Events

Weight M-H, Random, 95\% CI

M-H, Random, 95\% CI

\begin{tabular}{|c|c|c|c|c|c|c|}
\hline GOG 122 & 55 & 139 & 81 & 151 & $65.6 \%$ & $0.74[0.57,0.95]$ \\
\hline Maggi 2006 & 37 & 115 & 44 & 109 & $34.4 \%$ & $0.80[0.56,1.13]$ \\
\hline Total $(95 \%$ CI) & & 254 & & 260 & $100.0 \%$ & $0.76[0.62,0.93]$ \\
\hline Total events: & 92 & & 125 & & & \\
\hline
\end{tabular}

Heterogeneity: $\mathrm{Tau}^{2}=0.00 ; \mathrm{Chi}^{2}=0.12, \mathrm{df}=1(\mathrm{P}=0.72) ; \mathrm{I}^{2}=0 \%$

Test for overall effect: $\mathrm{Z}=2.65(\mathrm{P}=0.008)$

Test for subgroup differences: Not applicable

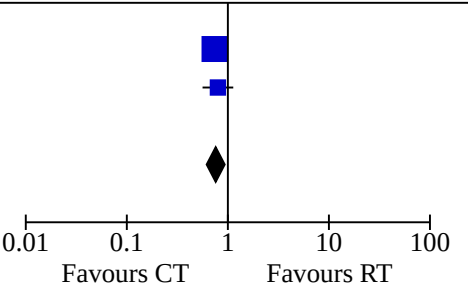


Analysis 1.8. Comparison 1: Chemotherapy vs radiotherapy, Outcome 8: PFS (Stage III only)

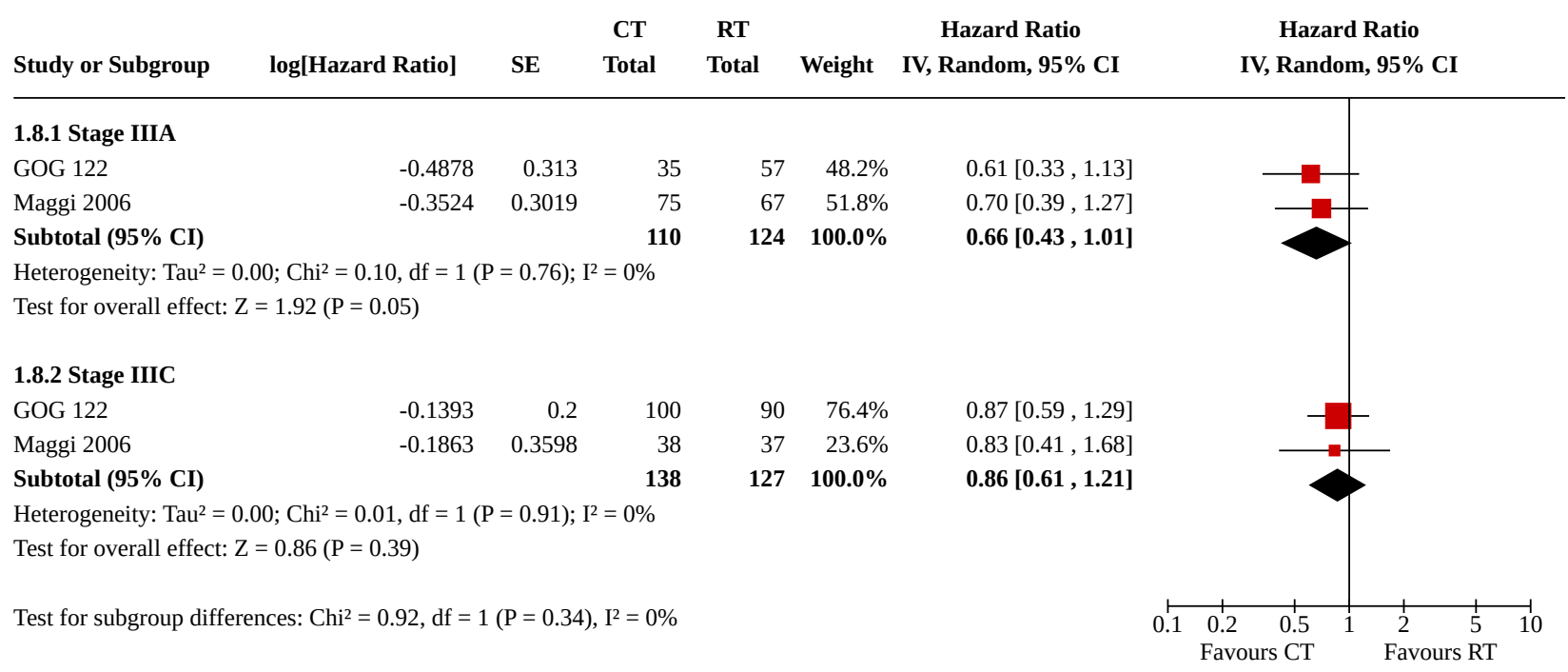

Analysis 1.9. Comparison 1: Chemotherapy vs radiotherapy, Outcome 9: PFS (Stage III dichotomous)

CT RT $\quad$ Risk Ratio $\quad$ Risk Ratio

Study or Subgroup $\quad$ Events Total $\quad$ Events $\quad$ Total $\quad$ Weight $\quad$ M-H, Random, 95\% CI $\quad$ M-H, Random, 95\% CI

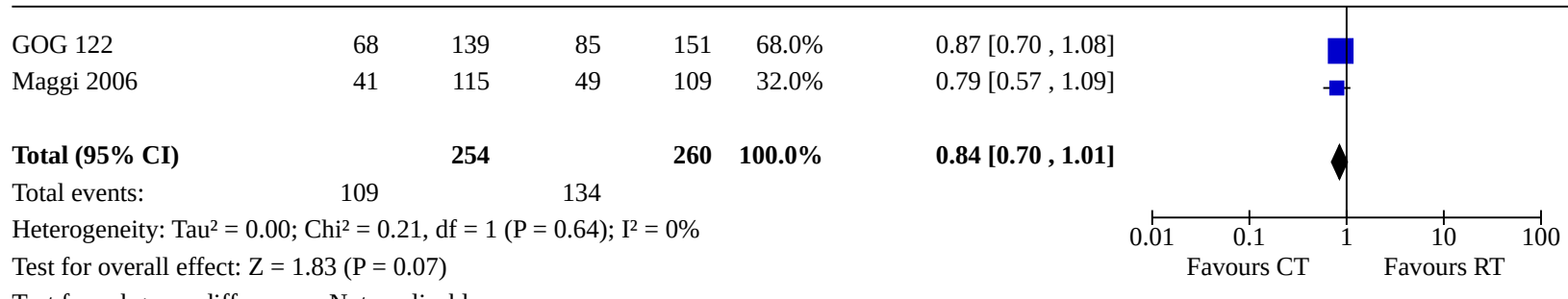


Analysis 1.10. Comparison 1: Chemotherapy vs radiotherapy, Outcome 10: Severe adverse events (G3/4)

CT

RT

Risk Ratio

Risk Ratio

Study or Subgroup Events Total Events

Total M-H, Random, 95\% CI M-H, Random, 95\% CI

1.10.1 Leukopenia

GOG 122

118

191

190

$13.04[6.83,24.92]$

1.10.2 Neutropenia

GOG 122

1.10.3 Thrombocytopenia

GOG 122

1.10.4 Gastrointestinal GOG 122

1.10.5 Neurological

GOG 122

\subsubsection{Infection}

GOG 122

1.10.7 Skin

GOG 122

1.10.8 Genitourinary GOG 122

1.10.9 Alopecia GOG 122

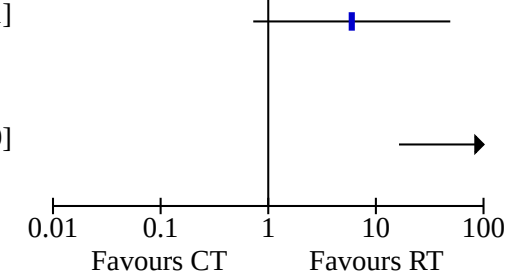

\section{Analysis 1.11. Comparison 1: Chemotherapy vs radiotherapy, Outcome 11: Treatment discontinuation due to toxicity}

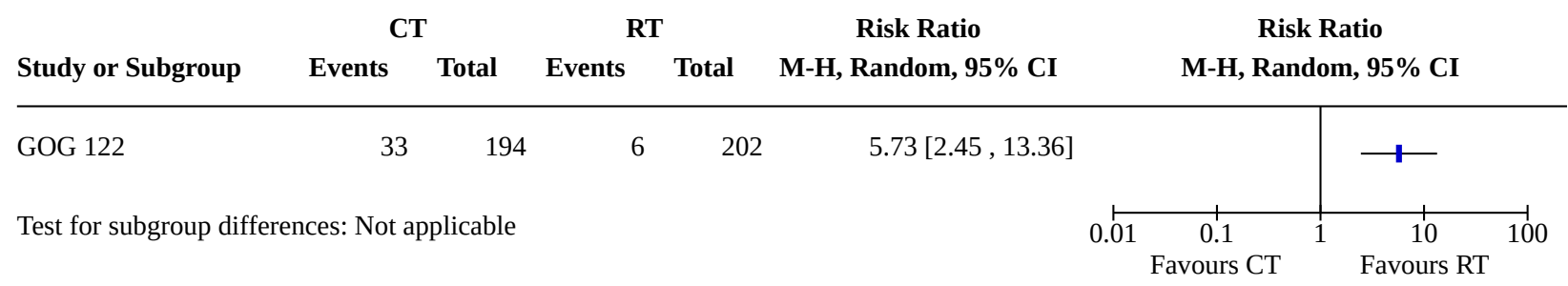


Analysis 1.12. Comparison 1: Chemotherapy vs radiotherapy, Outcome 12: Treatment-related deaths

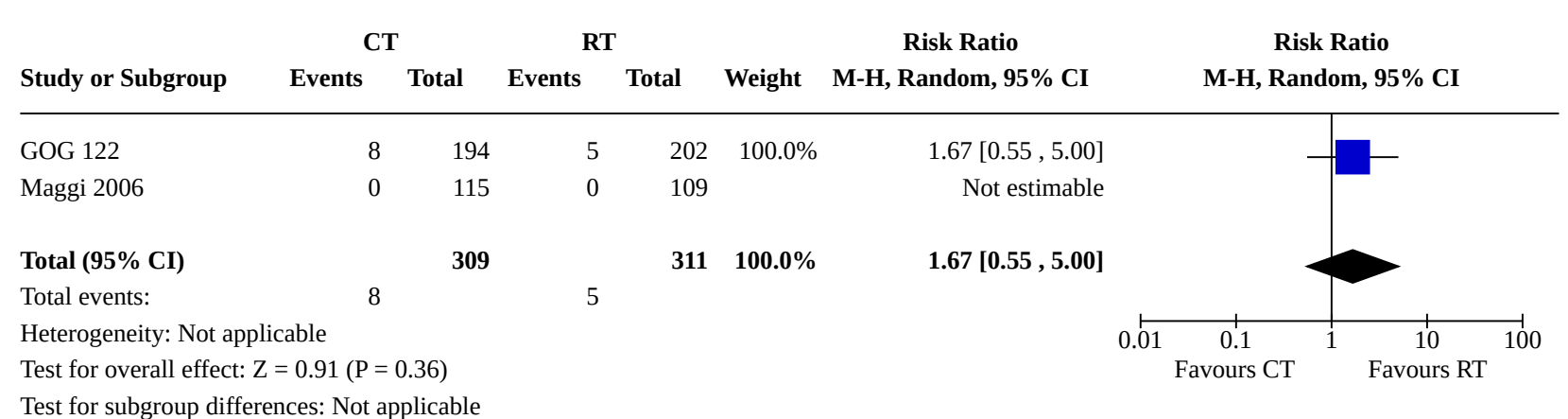

\section{Comparison 2. CDP vs CD}

\begin{tabular}{|c|c|c|c|c|}
\hline $\begin{array}{l}\text { Outcome or subgroup } \\
\text { title }\end{array}$ & No. of studies & $\begin{array}{l}\text { No. of partici- } \\
\text { pants }\end{array}$ & Statistical method & Effect size \\
\hline 2.1 OS (stage III/IV) & 1 & 552 & Hazard Ratio (IV, Random, 95\% Cl) & Not estimable \\
\hline 2.2 PFS (stage III/IV) & 1 & & Hazard Ratio (IV, Random, 95\% Cl) & Subtotals only \\
\hline $\begin{array}{l}\text { 2.3 Severe adverse } \\
\text { events }(G 3 / 4)\end{array}$ & 1 & & Risk Ratio (M-H, Random, 95\% Cl) & Totals not selected \\
\hline 2.3.1 Leukopenia & 1 & & Risk Ratio (M-H, Random, 95\% Cl) & Totals not selected \\
\hline 2.3.2 Neutropenia & 1 & & Risk Ratio (M-H, Random, 95\% Cl) & Totals not selected \\
\hline 2.3.3 Anaemia & 1 & & Risk Ratio (M-H, Random, 95\% Cl) & Totals not selected \\
\hline 2.3.4 Thrombocytopenia & 1 & & Risk Ratio (M-H, Random, 95\% Cl) & Totals not selected \\
\hline 2.3.5 Gastrointestinal & 1 & & Risk Ratio (M-H, Random, 95\% Cl) & Totals not selected \\
\hline 2.3.6 Neurological & 1 & & Risk Ratio (M-H, Random, 95\% Cl) & Totals not selected \\
\hline 2.3.7 Infection & 1 & & Risk Ratio (M-H, Random, 95\% Cl) & Totals not selected \\
\hline 2.3.8 Skin & 1 & & Risk Ratio (M-H, Random, 95\% Cl) & Totals not selected \\
\hline 2.3.9 Genitourinary & 1 & & Risk Ratio (M-H, Random, 95\% Cl) & Totals not selected \\
\hline 2.3.10 Pain & 1 & & Risk Ratio (M-H, Random, 95\% Cl) & Totals not selected \\
\hline $\begin{array}{l}2.4 \text { Treatment discontin- } \\
\text { uation }\end{array}$ & 1 & & Risk Ratio (M-H, Random, 95\% Cl) & Subtotals only \\
\hline
\end{tabular}


Analysis 2.1. Comparison 2: CDP vs CD, Outcome 1: OS (stage III/IV)

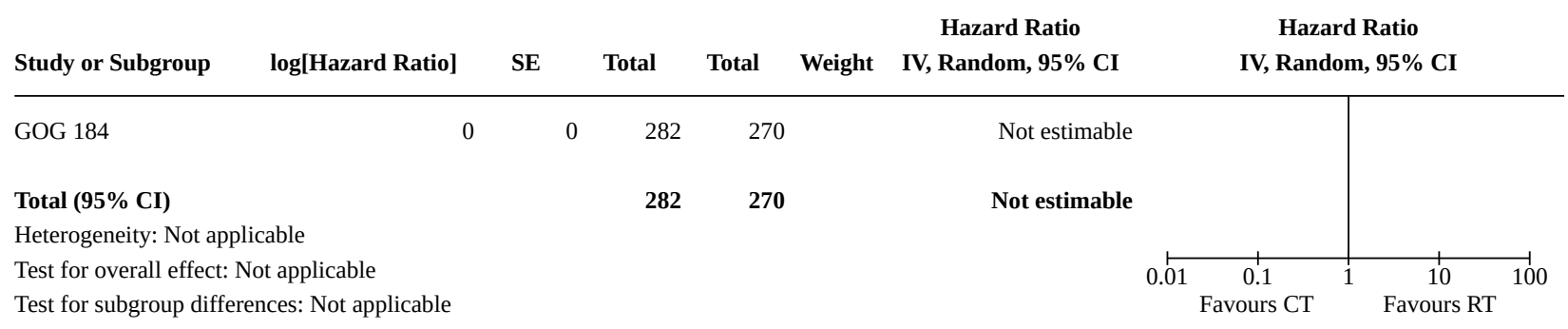

Analysis 2.2. Comparison 2: CDP vs CD, Outcome 2: PFS (stage III/IV)

$\begin{array}{lcccccc} & & \text { CDP } & \text { CD } & \text { Hazard Ratio } & \text { Hazard Ratio } \\ \text { Study or Subgroup } & \log [\text { Hazard Ratio] } & \text { SE } & \text { Total } & \text { Total } & \text { IV, Random, 95\% CI } & \text { IV, Random, 95\% CI }\end{array}$

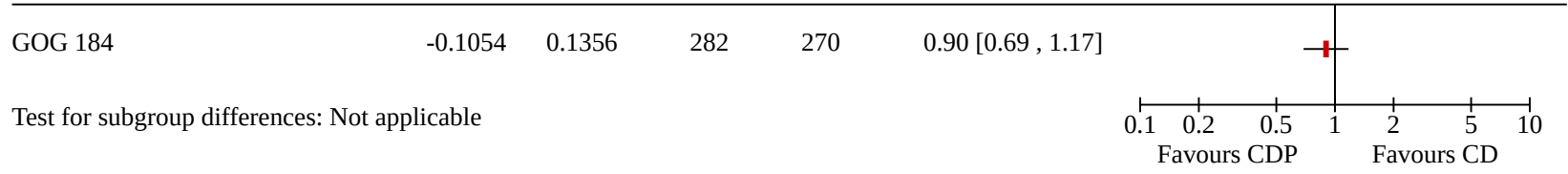


Analysis 2.3. Comparison 2: CDP vs CD, Outcome 3: Severe adverse events (G3/4)

CDP Events Total
CD Events
Risk Ratio

Study or Subgroup

2.3.1 Leukopenia

GOG 184

213

278

132

261

2.3.2 Neutropenia

GOG 184

190

278

122

261

$43 \quad 278$

31

261

$1.30[0.85,2.00]$

2.3.3 Ana
GOG 184

2.3.4 Thrombocytopenia

GOG 184

2.3.5 Gastrointestinal

GOG 184

$21 \quad 278$

$24 \quad 278$

5

261

GOG 184

2.3.7 Infection

GOG 184

278

2

278

$4 \quad 278$

4

261

GOG 184

2.3.10 Pain

GOG 184
$0.94[0.24,3.72]$

$1.49[0.83,2.67]$

$2.33[1.54,3.52]$

$1.23[0.66,2.31]$

$4.51[1.75,11.64]$

$5.16[1.80,14.78]$

$1.88[0.17,20.58]$

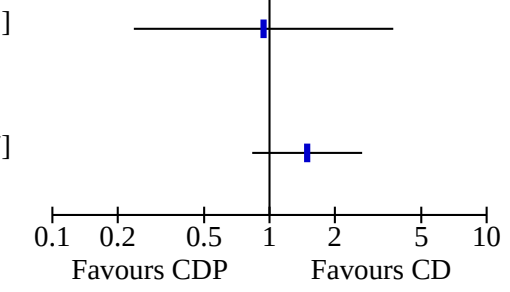

Analysis 2.4. Comparison 2: CDP vs CD, Outcome 4: Treatment discontinuation

\begin{tabular}{|c|c|c|c|c|c|c|c|c|}
\hline \multirow[b]{2}{*}{ Study or Subgroup } & \multicolumn{2}{|c|}{ CDP } & \multicolumn{2}{|c|}{ CD } & \multirow{2}{*}{$\begin{array}{c}\text { Risk Ratio } \\
\text { M-H, Random, 95\% CI }\end{array}$} & \multirow{2}{*}{\multicolumn{3}{|c|}{$\begin{array}{c}\text { Risk Ratio } \\
\text { M-H, Random, 95\% CI }\end{array}$}} \\
\hline & Events & Total & Events & Total & & & & \\
\hline GOG 184 & 32 & 282 & 20 & 270 & $1.53[0.90,2.61]$ & & & $1-$ \\
\hline \multicolumn{6}{|c|}{ Test for subgroup differences: Not applicable } & 0.01 & $\begin{array}{c}0.1 \\
\text { ours CDP }\end{array}$ & $\begin{array}{cc}1 & 1 \\
1 & \text { Favours }\end{array}$ \\
\hline
\end{tabular}

\section{AP PEN DICES}

\section{Appendix 1. Medline search strategy}

1 exp Endometrial Neoplasms/ 
2 (endometri* adj5 (cancer* or tumor ${ }^{\star}$ or tumour ${ }^{\star}$ or neoplas* or malignan* or carcinoma* or adenocarcinoma*)).mp

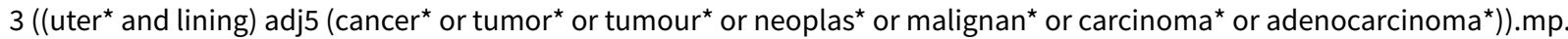

41 or 2 or 3

5 surgery.fs.

6 exp Surgical Procedures, Operative/

7 (surgery or surgical).mp.

85 or 6 or 7

9 drug therapy.fs.

10 exp Antineoplastic Agents/

11 Antineoplastic Combined Chemotherapy Protocols/

12 chemotherap ${ }^{\star} . \mathrm{mp}$.

139 or 10 or 11 or 12

144 and 8 and 13

15 randomized controlled trial.pt

16 controlled clinical trial.pt.

17 randomized.ab.

18 placebo.ab.

19 clinical trials as topic.sh.

20 randomly.ab.

21 trial.ti.

2215 or 16 or 17 or 18 or 19 or 20 or 21

2314 and 22

key:

[mp=title, abstract, original title, name of substance word, subject heading word, keyword heading word, protocol supplementary concept, rare disease supplementary concept, unique identifier]

\section{Appendix 2. EMBASE search strategy}

1 exp endometrium tumor/

2 (endometri ${ }^{\star}$ adj5 (cancer ${ }^{\star}$ or tumor ${ }^{\star}$ or tumour ${ }^{\star}$ or neoplas* or malignan $^{\star}$ or carcinoma* $^{\star}$ or adenocarcinoma*)).mp.

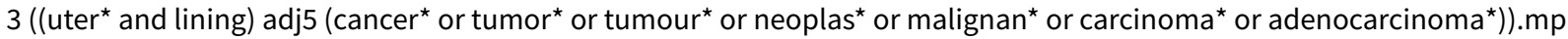

41 or 2 or 3

5 su.fs.

6 exp surgery/

7 (surgery or surgical).mp.

85 or 6 or 7

$9 \mathrm{dt} . \mathrm{fs}$.

10 exp chemotherapy/

11 exp antineoplastic agent/

12 chemotherap ${ }^{\star} . \mathrm{mp}$.

139 or 10 or 11 or 12

144 and 8 and 13

15 crossover procedure/

16 double-blind procedure/

17 randomized controlled trial/

18 single-blind procedure/

19 random*.mp.

20 factorial $^{*} . \mathrm{mp}$.

21 (crossover ${ }^{\star}$ or cross over ${ }^{\star}$ or cross-over ${ }^{\star}$ ).mp.

22 placebo*.mp.

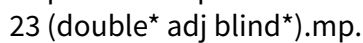

24 (singl $^{\star}$ adj blind $\left.^{\star}\right)$.mp.

25 assign $^{\star} . \mathrm{mp}$.

26 allocat*.mp.

27 volunteer ${ }^{\star} . \mathrm{mp}$.

2815 or 16 or 17 or 18 or 19 or 20 or 21 or 22 or 23 or 24 or 25 or 26 or 27

2914 and 28

key: [mp=title, abstract, subject headings, heading word, drug trade name, original title, device manufacturer, drug manufacturer, device trade name, keyword] 


\section{Appendix 3. CENTRAL search strategy}

\#1 MeSH descriptor: [Endometrial Neoplasms] explode all trees

\#2 endometri* near/5 (cancer* or tumor* or tumoour* or neoplas* or malignan* or carcinoma* or adenocarcinoma*)

\#3 (uter ${ }^{\star}$ and lining) near/5 (cancer ${ }^{\star}$ or tumor $^{\star}$ or tumour $^{\star}$ or neoplas ${ }^{\star}$ or malignan ${ }^{\star}$ or carcinoma* or adenocarcinoma* $^{\star}$ )

\#4 \#1 or \#2 or \#3

\#5 Any MeSH descriptor with qualifier(s): [Surgery - SU]

\#6 MeSH descriptor: [Surgical Procedures, Operative] explode all trees

\#7 surgery or surgical

\#8 \#5 or \#6 or \#7

\#9 Any MeSH descriptor with qualifier(s): [Drug therapy - DT]

\#10 MeSH descriptor: [Antineoplastic Agents] explode all trees

\#11 MeSH descriptor: [Antineoplastic Combined Chemotherapy Protocols] explode all trees

\#12 chemotherap*

\#13 \#9 or \#10 or \#11 or \#12

$\# 14$ \#4 and \#8 and \#13

\section{WHAT'S NEW}

\begin{tabular}{lll}
\hline Date & Event & Description \\
\hline 20 May 2021 & Review declared as stable & $\begin{array}{l}\text { This review will be superseded by an ongoing review which } \\
\text { widens the scope of the review. }\end{array}$ \\
\hline
\end{tabular}

\section{H I S T O R Y}

Protocol first published: Issue 8, 2013

Review first published: Issue 5, 2014

\begin{tabular}{lll}
\hline Date & Event & Description \\
\hline 5 December 2018 & Review declared as stable & No new trials expected in this topic area. \\
\hline 1 April 2015 & Amended & Contact details updated. \\
\hline 11 February 2015 & Amended & Contact details updated. \\
\hline 11 November 2013 & Amended & New search performed. \\
\hline
\end{tabular}

\section{CONTRIBUTIONS OF AUTHORS}

KG wrote the protocol, selected trials, checked extracted data, and co-wrote the manuscript. TAL selected and classified trials, contacted trial investigators, extracted data and co-wrote the manuscript. AB checked extracted data and provided statistical support. MAM and AL critically appraised drafts of the review. All authors approved the final version.

\section{DECLARATIONS OF INTEREST}

None

\section{SOURCES OF SUPPORT}

\section{Internal sources}

- No sources of support provided 


\section{External sources}

- Department of Health, UK

NHS Cochrane Collaboration Programme Grant Scheme CPG-10/4001/12

\section{DIFFERENCES BETWEEN PROTOCOLANDREVIEW}

The title of the original protocol was 'Surgery and chemotherapy with or without radiotherapy for disseminated advanced endometrial cancer' (Galaal 2013). We rephrased the types of interventions for clarity.

\section{N O T E S}

This review will be superseded by an ongoing review which widens the scope of the review.

\section{N DEX TERMS}

\section{Medical Subject Headings (MeSH)}

Antineoplastic Combined Chemotherapy Protocols [*therapeutic use]; Chemoradiotherapy; Chemotherapy, Adjuvant [adverse effects] [methods] [mortality]; Cisplatin [administration \& dosage]; Disease-Free Survival; Doxorubicin [administration \& dosage]; Endometrial Neoplasms [*drug therapy] [mortality] [pathology] [therapy]; Neoplasm Staging; Paclitaxel [administration \& dosage]; Radiotherapy, Adjuvant; Randomized Controlled Trials as Topic

\section{MeSH check words}

Female; Humans 